\title{
Transcriptomic analysis of the dialogue between Pseudorabies virus and porcine epithelial cells during infection Laurence Flori*1, Claire Rogel-Gaillard ${ }^{1}$, Marielle Cochet ${ }^{2}$, Gaetan Lemonnier ${ }^{1}$, Karine Hugot ${ }^{1}$, Patrick Chardon ${ }^{1}$, Stéphane Robin ${ }^{3}$ and François Lefèvre ${ }^{2}$
}

Address: 1INRA, DGA, UMR 314, Laboratoire de Radiobiologie et d'Etude du Génome, Jouy-en-Josas, F-78350 France; CEA, DSV, IRCM, SREIT, Laboratoire de Radiobiologie et d'Etude du Génome, Jouy-en-Josas, F-78350, France, '2INRA, DSA, UR892, Unité de Virologie et Immunologie Moléculaires, Jouy-en-Josas, F-78350, France and ${ }^{3}$ AgroParisTech-ENGREF-INRA, UMR 518, Unité de Mathématiques et Informatique Appliquées, Paris F-75005, France

Email: Laurence Flori* - laurence.flori@jouy.inra.fr; Claire Rogel-Gaillard -rogel-gaillard@jouy.inra.fr; Marielle Cochet - marielle.bernoin@jouy.inra.fr; Gaetan Lemonnier - gaetan.lemonnier@jouy.inra.fr; Karine Hugot - karine.hugot@jouy.inra.fr; Patrick Chardon - patrick.chardon@jouy.inra.fr; Stéphane Robin - robin@inapg.fr; François Lefèvre - francois.lefevre@jouy.inra.fr

* Corresponding author

Published: 10 March 2008

BMC Genomics 2008, 9:123 doi:10.1/86/147|-2164-9-123
Received: 20 August 2007

Accepted: 10 March 2008

This article is available from: http://www.biomedcentral.com//47I-2/64/9//23

(C) 2008 Flori et al; licensee BioMed Central Ltd.

This is an Open Access article distributed under the terms of the Creative Commons Attribution License (http://creativecommons.org/licenses/by/2.0), which permits unrestricted use, distribution, and reproduction in any medium, provided the original work is properly cited.

\begin{abstract}
Background: Transcriptomic approaches are relevant for studying virus-host cell dialogues to better understand the physiopathology of infection and the immune response at the cellular level. Pseudorabies virus (PrV), a porcine Alphaherpesvirus, is a good model for such studies in pig. Since PrV displays a strong tropism for mucous epithelial cells, we developed a kinetics study of PrV infection in the porcine PKI5 epithelial cell line. To identify as completely as possible, viral and cellular genes regulated during infection, we simultaneously analyzed $\operatorname{Pr} V$ and cellular transcriptome modifications using two microarrays i.e. a laboratory-made combined SLA/PrV microarray, consisting of probes for all PrV genes and for porcine genes contained in the Swine Leukocyte Antigen (SLA) complex, and the porcine generic Qiagen-NRSP8 oligonucleotide microarray. We confirmed the differential expression of a selected set of genes by qRT-PCR and flow cytometry.
\end{abstract}

Results: An increase in the number of differentially expressed cellular genes and $\operatorname{Pr} V$ genes especially from $4 \mathrm{~h}$ post-infection ( $\mathrm{pi}$ ) was observed concomitantly with the onset of viral progeny while no early global cellular shutoff was recorded. Many cellular genes were down-regulated from $4 \mathrm{~h}$ pi and their number increased until 12 h pi. UL4I transcripts encoding the virion host shutoff protein were first detected as differentially expressed at 8 $\mathrm{h}$ pi. The viral gene UL49.5 encoding a TAP inhibitor protein was differentially expressed as soon as $2 \mathrm{~h} \mathrm{pi}$, indicating that viral evasion via TAP inhibition may start earlier than the cellular gene shutoff. We found that many biological processes are altered during $\operatorname{PrV}$ infection. Indeed, several genes involved in the SLA class I antigenic presentation pathway (SLA-la, TAPI, TAP2, PSMB8 and PSMB9), were down-regulated, thus contributing to viral immune escape from this pathway and other genes involved in apoptosis, nucleic acid metabolism, cytoskeleton signaling as well as interferon-mediated antiviral response were also modulated during $\operatorname{PrV}$ infection.

Conclusion: Our results show that the gene expression of both $\operatorname{PrV}$ and porcine cells can be analyzed simultaneously with microarrays, providing a chronology of $\operatorname{PrV}$ gene transcription, which has never been described before, and a global picture of transcription with a direct temporal link between viral and host gene expression. 


\section{Background}

In vitro analyses of host cell/pathogen interactions are essential to unravel the mechanisms of infection and to investigate the host response to infection. Pseudorabies virus (PrV) belongs to the Alphaherpesvirinae subfamily as for example the human herpes simplex virus 1 (HSV-1) and is a well-known pig pathogen responsible for Aujeszky's disease, causing considerable economical losses worldwide in this species [1]. Although some countries have succeeded in eradicating Aujeszky's disease through vaccination and health policies, the disease prevalence still remains variable in other countries. Young piglets are more severely affected by $\operatorname{PrV}$ infection often resulting in fatal encephalitis, than older infected pigs, which can remain asymptomatic or develop mild to severe respiratory disease symptoms associated with a limited mortality. Indeed, PrV displays a strong tropism for epithelial cells of the oronasal respiratory tract, which are the first cells targeted by virions [1,2]. Abortions, stillbirths or weak piglets that die within $48 \mathrm{~h}$ of birth are also observed when pregnant sows are infected [1]. Moreover, PrV can infect a broad range of vertebrates resulting in a uniform lethality but it is generally considered as a nonpathogenic agent for man [3]. Because PrV is easy to propagate in cells of several mammalian species including rodents and is not harmful to laboratory workers, $\mathrm{PrV}$ is a highly relevant model to study the biology of alphaherpesviruses and their interactions with host cells in vitro [1]. In addition, its genome has been reconstructed from sequences of six different strains (Kaplan, Becker, Rice, Indiana-Funkhauser, NIA-3, and TNL) and 70 genes encoding structural and non structural proteins have been annotated [4].

Viruses have evolved strategies to evade the host immune response. In particular, herpesviruses interfere with the Major Histocompatibility Complex (MHC) class I antigen presentation pathway to avoid the Cytotoxic T Lymphocyte (CTL) response [5]. MHC class I molecules are expressed on almost all nucleated cells and present peptides, including peptides derived from viral antigens, to $\mathrm{CTL}$, which play a critical role in the defense mechanisms against viral infection. It has been reported that PrV infection decreases the expression of MHC class I molecules on the cell surface [6]. This down-regulation is partly explained by the inhibition of the $\mathrm{ABC}$ transporter TAP activity, due to interactions with the viral gN protein encoded by the UL49.5 gene $[7,8]$. This inhibition is independent of the non-specific mRNA cellular shut-off produced by the virion host shut-off (vhs) protein encoded by the UL41 gene [9]. However, mechanisms other than TAP inhibition may be involved in avoiding the MHC class I presentation pathway.
A precise and more complete identification of cellular and viral genes, which are up- or down-regulated during the time course of infection, is essential to better understand the physiopathology of infection and to identify the molecules involved in host resistance/susceptibility mechanisms. During recent years, DNA microarray technology has proven to be a very efficient high-throughput tool to study the gene expression profiles of infected host cells or pathogens $[10,11]$. To date, three transcriptomic analyses focused on cellular gene expression have been carried out in non-porcine PrV infected cells [12-14]. Ray and Enquist have compared the cellular pathways regulated by $\operatorname{PrV}$ and HSV-1 during infection of rat embryonic fibroblast cells using a rat microarray [12]. In a similar system, Brukman and Enquist have explored how PrV evades the IFNmediated immune response [13]. Finally, Blanchard et al have used a human microarray to characterize the impact of PrV infection in human embryonic kidney cells (HEK293) [14]. These studies have identified many biological processes and host cell genes regulated during infection. The next step in a transcriptomic approach would be the simultaneous analysis of viral and cellular modifications of transcription during $\operatorname{PrV}$ infection $[10,11]$ using porcine genomic tools. Since the pig whole genome assembly is not yet achieved, no complete pan-genomic array exists and only partial generic microarrays are commercially available [15]. However, the pig MHC region referred to as the SLA (Swine Leukocyte Antigen) complex, located on chromosome 7 , is the first region of the pig genome that is entirely sequenced and annotated [16].

In this context, our aim was to study the dialogue between PrV and the PK15 porcine epithelial cell line, which mimics the first porcine target cells. Using two different porcine microarrays, we followed both the viral and cellular transcriptome kinetics during infection. These microarrays were the Qiagen-NRSP8 commercial array [17] and a microarray we constructed, referred to as SLA/PrV, which combines probe sets specific to genes localized in the SLA complex, genes encoding other important immunological molecules [18] and all the PrV genes. Here, we present a large-scale analysis of the porcine physiological pathways regulated during viral infection with a special focus on genes in the SLA complex together with the modifications of the PrV transcriptome.

\section{Results \\ Construction of the SLAIPrV microarray and complementarity with the Qiagen-NRSP8 microarray}

The 1789 DNA/cDNA probes spotted on the SLA/PrV microarray fall into four distinct probe sets: i) 420 probes localized on a segment of chromosome 7 between the loci PRL and PRIM2A (SSC7p1.1-q1.2), which includes the extended-SLA region and represents 272 unique sequences, 111 belonging to the strict SLA region between 
the loci UBD and RING1 [16]; ii) 73 probes specific to 73 genes encoding molecules involved in immunity and localized outside the SLA region [18]; iii) $80 \mathrm{PrV}$ probes specific to the 70 viral genes (Figure 1) and iv) 1170 probes randomly chosen for data normalization from porcine cDNA AGENAE library $[19,20]$. The PrV/SLA microarray covers $72.5 \%$ of the annotated sequences of the strict SLA region $(=111 / 153)[16,21]$.

The Qiagen-NRSP8 oligonucleotide microarray contains 13297 probes, which match 8541 unique human or mouse RefSeq or pig annotated gene NCBI accession numbers and $1.5 \%$ of these encode immune proteins [17]. Only 48 of the 420 probes from the extended SLA probe set and 41 of the 73 from the immune probe set are present on both microarrays.

\section{Expression of PrV genes during the time course of infection} The six time points, which were studied in this experiment - i.e. $0,1,2,4,8$ and 12 hours (h) post-infection (pi), were chosen according to viral growth kinetics observed in
PK15 cells in our experimental conditions (Figure 2). The expression of viral genes was detected between 2 and $12 \mathrm{~h}$ pi and increased during time and most of the genes were expressed at 8 and $12 \mathrm{~h}$ pi. The hierarchical clustering (HCL) of viral gene expression levels according to all conditions (time and infection status) allowed us to distinguish two main groups: i) mock-infection at all time points and infection until $2 \mathrm{~h}$ pi ii) infection from 4 until $12 \mathrm{~h}$ (data not shown). With the k-means method, we identified three transcript clusters with similar expression profiles (Figure 3). The average expression levels for the first cluster (29 probes) showed little variation and only from $8 \mathrm{~h}$ pi. The second cluster contained 30 probes corresponding to genes, the expression level of which increased from $4 \mathrm{~h}$ pi. The last group (21 probes) displayed a higher increase of expression level from 2 to $8 \mathrm{~h}$ pi.

Using a linear model and student $t$ tests, the analysis of viral genes, which were differentially expressed between infected and mock-infected cells at each time pi (FDR =

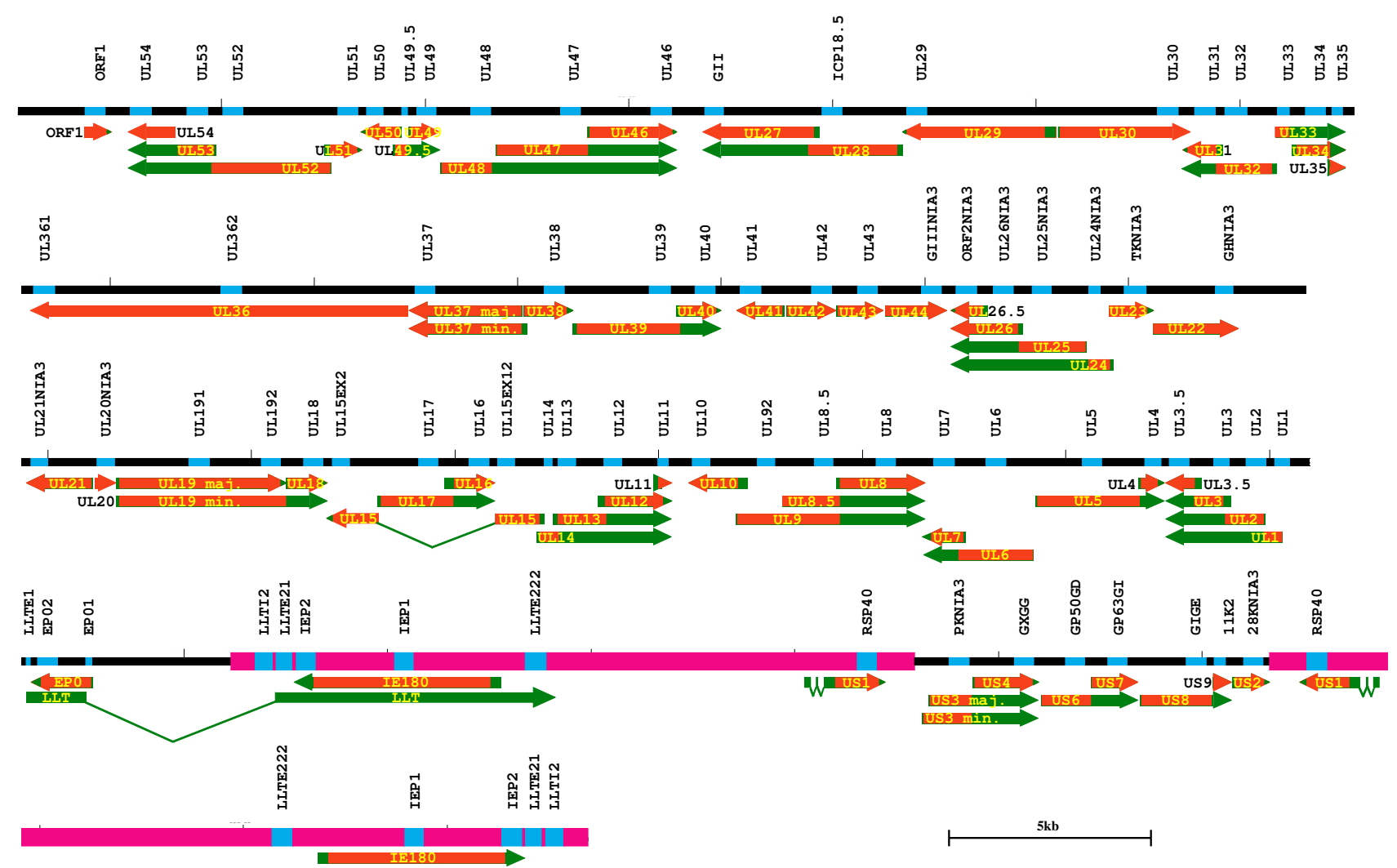

Figure I

Map of the PrV transcriptome. The relative location of transcripts and designed amplicons are shown. UL and US regions of the PrV genome are represented in black while IR and TR regions are in pink. Transcripts corresponding to each gene are represented with arrows (coding region in orange and non-coding regions or introns in green). Amplicons are represented in blue on the genome. The name of each amplicon is written above the corresponding genome location. Size is measured in kb. 


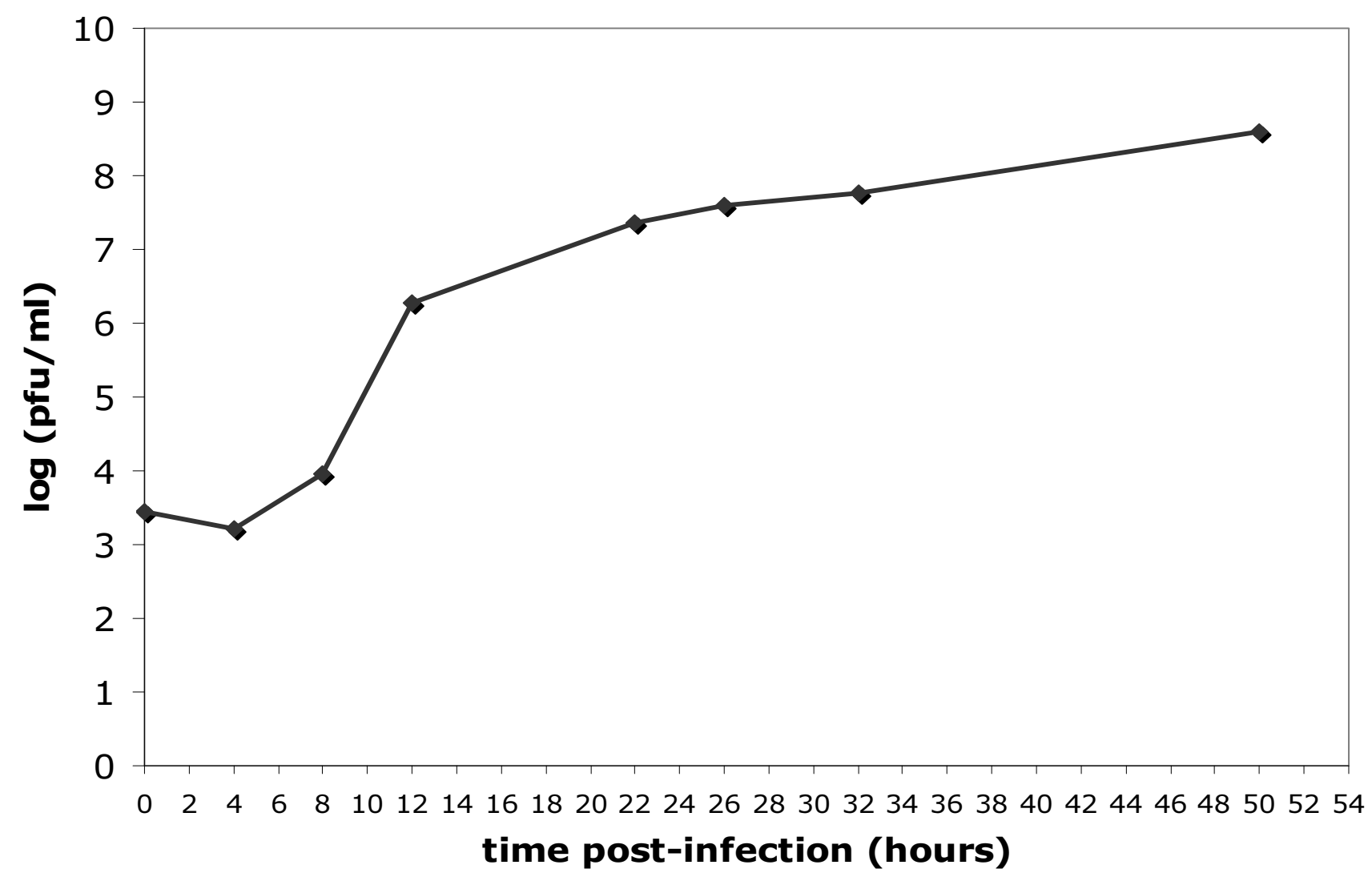

Figure 2

PrV growth kinetics in PKI 5 cells. The PKI 5 cells were infected with PrV NIA3 at 20 MOI in HMS-M medium. PrV was titrated in the medium by plaque assay at different times pi $(0,4,8,12,22,26,32$ and $50 \mathrm{~h}$ pi). PrV titer was expressed as plaque forming units per $\mathrm{ml}(\mathrm{pfu} / \mathrm{ml})$.

$0.05)$ indicated that three differentially expressed probes were observed as soon as $1 \mathrm{~h}$ pi and that this number increased drastically between 2 and 8 h $(39$ additional probes) and reached a plateau after $8 \mathrm{~h}$ pi (Table 1 ). The important increase between 4 and $8 \mathrm{~h}$ confirmed the HCL and k-means results and correlated with the PrV growth curve (Figure 2). Nineteen probes were not differentially expressed between infected and mock-infected cells at any time and 16 of them were found in the less variable cluster by the k-means method (Figure 3). Most of the differentially expressed probes belonged to the two most variable clusters. Among the 58 differentially expressed probes, 26 recognized two to four transcripts and 32 were specific to a single transcript (Table 2). When examining these latter 32 genes, the first differentially expressed genes observed $1 \mathrm{~h}$ pi were US1 and UL29 encoding two non structural proteins RSP40 and ICP8, respectively, and UL49.5 encoding the virion envelope glycoprotein gN. However, IE180 encoding the immediate early protein IEP, a transactivator of early gene expression was found differentially expressed at $4 \mathrm{~h}$ pi. Moreover, the four genes, which were differentially expressed between 8 and 12 h, specify non structural (UL9), capsid (UL28), tegument (UL36) and envelope (US8) transcripts. The differential expression of UL41 encoding vhs protein was first detected at $8 \mathrm{~h}$ pi. Among the probes recognizing two transcripts, PKNIA3 specific of US3min and US3maj involved in the inhibition of apoptosis was also differentially expressed from 8 h pi and UL37 specific of UL37 min and UL37maj encoding a tegument protein was differentially expressed at 12 h pi.

\section{Global PKI 5 differential gene expression during the time course of infection}

The number of differentially expressed cellular probes increased with time in parallel to viral gene expression (Table 1). Between 0 and $2 \mathrm{~h}$ pi most of the SLA/immune probes showed no change and few differentially expressed genes were detected from $1 \mathrm{~h}$ pi with the Qiagen-NRPS8 microarray (Table 1). As shown in Table 1, the SLA/PrV microarray identified 1, 0, 2, 36, 107 and 107 differentially expressed probes at $0,1,2,4,8$ and $12 \mathrm{~h}$ pi, respec- 


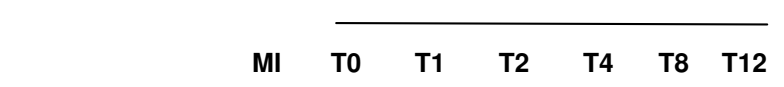

\section{Cluster 1}

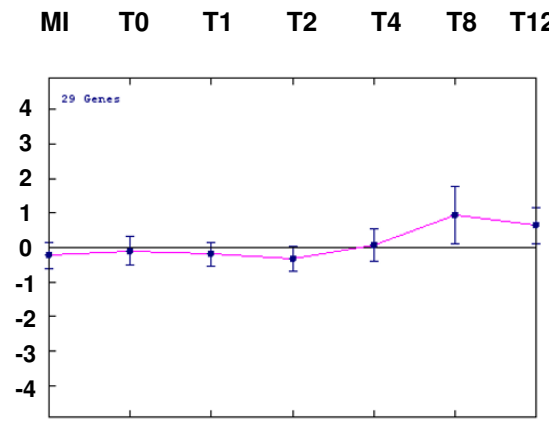

Cluster 2

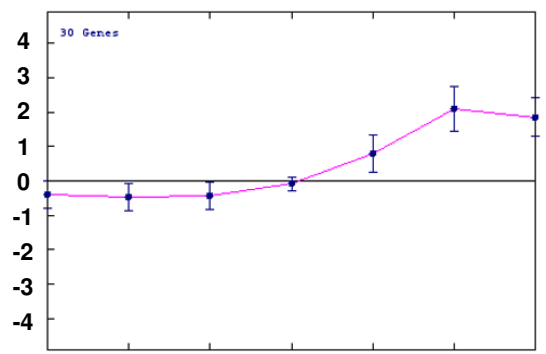

Cluster 3

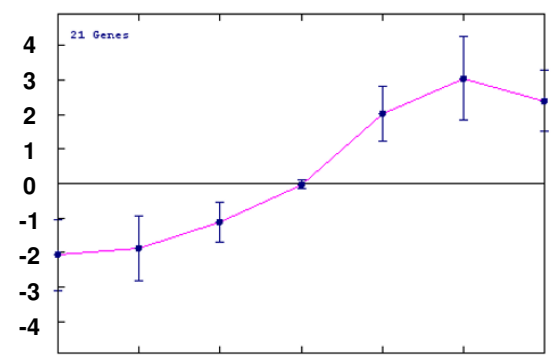

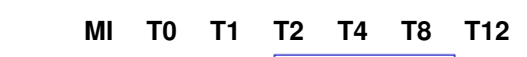
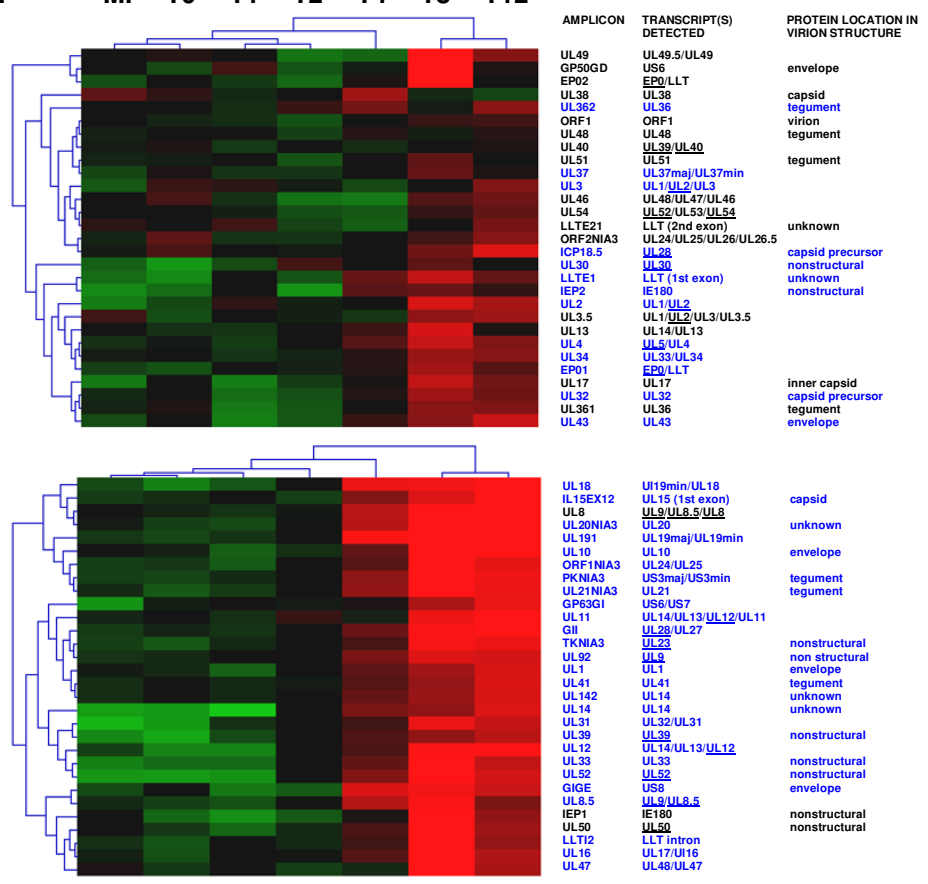

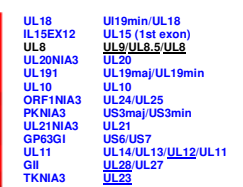

capsid

unimourm

tegument

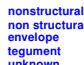 \\ unknown

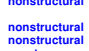 \\ nonstrutural
nonstructural}

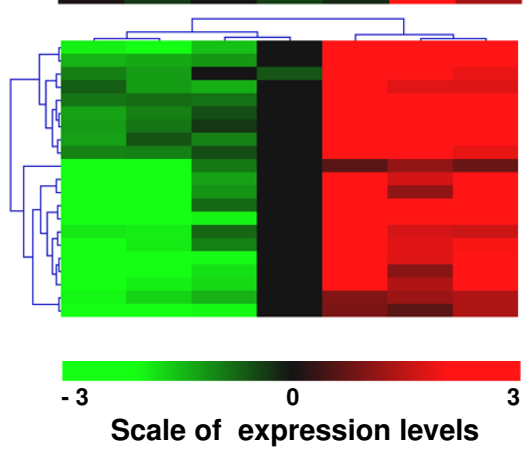

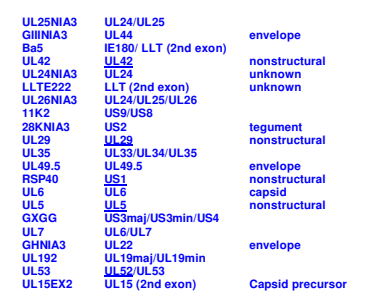

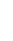

\section{Figure 3}

Clusters of PrV gene expression levels identified by the k-means method. The average of normalized intensities for all mock-infected conditions and for each infected condition, centered (median) by genes were analyzed with the k-means method (three clusters). For each cluster, one graph and one clustering picture are represented. The graph shows the mean of the expression levels of all genes ( $x=$ Time; $y=$ mean of levels of expression). The clustering picture depicts the mean of each gene expression level for all mock-infected time points and for each infected time point $(x=$ Time; $y=$ level of expression). The list of $\mathrm{PrV}$ amplicons belonging to each cluster, the list of the corresponding viral genes and the location of the corresponding proteins in virion structure (for amplicons that hybridize to a single transcript) are represented on the right. The names of the probes that are differentially expressed are represented in blue. To distinguish immediate early, early and late genes, early genes are underlined. All other genes are late genes except IEI 80 which is the only immediate early gene of PrV.

tively [see Additional file 1] and the Qiagen-NRSP8 microarray identified 31, 181, 2756, 6693 differentially expressed probes at 1, 2, 4 and $8 \mathrm{~h}$ pi [see Additional file $2]$, respectively. The SLA/PrV microarray data show that $86(31 / 36), 82(88 / 107)$, and $87 \%(93 / 107)$ of the differentially expressed probes were down-regulated at 4,8 and $12 \mathrm{~h} \mathrm{pi}$, respectively and the Qiagen-NRSP8 microarray data show that $13(4 / 31), 26(47 / 181), 54(1494 / 2756)$ and $52 \%(3509 / 6693)$ of the differentially expressed probes explored in this case were down-regulated at 1, 2, 4 and $8 \mathrm{~h} \mathrm{pi}$, respectively (Table 1 ). With the k-means method, the expression levels for each condition (time and infection status) of the SLA/PrV differentially expressed probes set were clustered in three groups (Figure 
Table I: Number of viral and cellular probes differentially expressed at each time point.

\begin{tabular}{|c|c|c|c|c|c|c|c|c|}
\hline Probe set & Microarray & Probe subset & TO & $\mathrm{TI}$ & $\mathrm{T} 2$ & $\mathrm{~T} 4$ & T8 & TI2 \\
\hline \multirow[t]{2}{*}{$\operatorname{PrV}$} & SLA/PrV & Probes homologous to a single transcript & 0 & 3 & 7 & 18 & 26 & 30 \\
\hline & & Total & 0 & 3 & 13 & 34 & 52 & 58 \\
\hline \multirow[t]{8}{*}{ Pig } & SLA/PrV & up-regulated SLA/Immune probes & 0 & 0 & 0 & 1 & 4 & 3 \\
\hline & & down regulated SLA/Immune probes & 0 & 0 & 0 & 11 & 18 & 13 \\
\hline & & up-regulated random probes & I & 0 & 2 & 4 & 15 & 11 \\
\hline & & down-regulated random probes & 0 & 0 & 0 & 20 & 70 & 80 \\
\hline & & Total & 1 & 0 & 2 & 36 & 107 & 107 \\
\hline & Qiagen- NRSP8 & up-regulated probes & ND* & 27 & 134 & 1262 & 3184 & ND* \\
\hline & & down-regulated probes & ND* & 4 & 47 & 1494 & 3509 & ND* \\
\hline & & Total & ND* & 31 & 181 & 2756 & 6693 & ND* \\
\hline
\end{tabular}

*ND: not determined

4). Eighty-eight probes with a small decrease in expression levels from $4 \mathrm{~h}$ pi were found in the first cluster and 45 probes with a stronger decrease in expression levels from $2 \mathrm{~h}$ pi in the second cluster. The third cluster contained 27 up-regulated probes at $8 \mathrm{~h}$ pi. The results obtained with both microarrays show that many cellular genes were down-regulated during the time course of the experiment especially between 4 and $12 \mathrm{~h}$ pi.

\section{PrV infection alters multiple biological processes and cellular functions}

For each time point, the differentially expressed genes from the Qiagen-NRSP8 microarray were classified into biological processes using GO terms when available (Table 3). The biological processes that contained more than $5 \%$ of the differentially expressed genes during the period between 2 and $8 \mathrm{~h}$ pi included: protein metabolism and modification (BP0060), nucleoside, nucleotide and nucleic acid metabolism (BP00031), developmental process (BP00193), signal transduction (BP00102), transport (BP00141), cell cycle (BP00203), immunity and defense (BP00148), intracellular protein traffic (BP00125) and cell structure and motility (BP00285). Several biological processes were predominantly regulated $1 \mathrm{~h}$ pi such as developmental processes (BP00193) and signal transduction (BP00102). Other biological processes were regulated later such as cell adhesion (BP00124) or apoptosis (BP00179) from $2 \mathrm{~h}$ pi and homeostasis (BP00267) from $4 \mathrm{~h}$ pi.

The Ingenuity Pathway Analysis (IPA) of the differentially expressed probes from the Qiagen-NRSP8 microarray identified 82 different top functions associated with significant networks (Table 4). Three top functions were regulated early during infection ( $1 \mathrm{~h} \mathrm{pi}$ ): gene expression, molecular transport and drug metabolism. Sixteen, 68 and 67 top functions were modulated by PrV infection at 2, 4 and $8 \mathrm{~h}$ pi. Fifteen and 14 top functions were specific of time points 4 and $8 \mathrm{~h}$ pi, respectively. The number of regulated top functions strongly increased from $4 \mathrm{~h}$ pi. The top functions containing the highest number of focus genes at both 4 and $8 \mathrm{~h}$ pi were those involved in cancer, cell cycle and cell signaling with the first two detected as early as $2 \mathrm{~h}$ pi. Immune response and immunological disease top functions were found from $4 \mathrm{~h}$ pi and immune and lymphatic system development and function at $8 \mathrm{~h}$ pi. Cell death top function was first detected at $2 \mathrm{~h}$ pi.

\section{PrV infection modifies the expression of genes involved in MHC antigenic presentation pathways}

The expression of many genes belonging to the SLA class I antigenic presentation pathway was modulated during PrV infection according to the results of both microarrays (Table 5). SLA Ia genes were down-regulated from $4 \mathrm{~h}$ pi with the SLA/PrV microarray and from $8 \mathrm{~h}$ pi with the Qiagen-NRSP8 microarray. TAP1 and TAP2 genes, encoding molecules involved in peptide transport from the cytosol to the endoplasmic reticulum, were also down-regulated $8 \mathrm{~h} \mathrm{pi} \mathrm{according} \mathrm{to} \mathrm{the} \mathrm{results} \mathrm{of} \mathrm{the} \mathrm{Qiagen-NRSP8}$ microarray. Surprisingly, TAP1 was up-regulated $8 \mathrm{~h}$ pi with the SLA/PrV microarray. PSMB8 (alias LMP7), one of the genes encoding immunoproteasome molecules was up-regulated from $4 \mathrm{~h}$ pi on the Qiagen-NRSP8 microarray.

Unexpectedly, our results show that transcript levels of genes belonging to the MHC class II antigenic presentation pathway were also modulated during $\operatorname{PrV}$ infection. Expression of SLA-DOB and SLA-DMB decreased at $4 \mathrm{~h}$ pi according to the results from the SLA/PrV microarray (Table 5). SLA-DMB was also down-regulated with the Qiagen-NRSP8 microarray $8 \mathrm{~h}$ pi while SLA-DOA, SLADQA1 and CIITA were up-regulated at this time point (Table 5). 
Table 2: Viral probes and fold-change during infection kinetics.

\begin{tabular}{|c|c|c|c|c|c|c|c|c|c|}
\hline \multirow[t]{2}{*}{ Amplicon name } & \multirow[t]{2}{*}{ Transcript name } & \multicolumn{6}{|c|}{ Fold-change } & \multirow[t]{2}{*}{ Encoded protein and function* } & \multirow[t]{2}{*}{ Structural role* } \\
\hline & & T0 & TI & $\mathrm{T} 2$ & $\mathrm{~T} 4$ & T8 & $\mathrm{T} 12$ & & \\
\hline ORFI & ORFI & - & - & - & - & - & & unknown & virion \\
\hline UL54 & UL52/UL53/UL54 & - & - & - & - & - & - & & \\
\hline UL53 & UL52/UL53 & - & - & 4.6 & 6.6 & 6.7 & 7.4 & & \\
\hline UL52 & UL52 & - & - & - & 4.7 & 6.4 & 5.6 & $\begin{array}{l}\text { DNA replication; primase subunit of UL5/ } \\
\text { UL8/UL52complex }\end{array}$ & nonstructural \\
\hline UL5। & UL5I & - & - & - & - & - & - & viral egress & tegument \\
\hline UL50 & UL50 & - & - & - & - & - & - & dUTPase & nonstructural \\
\hline UL49.5 & UL49.5 & - & 4.4 & 6.4 & 9.0 & 10.4 & 13.5 & $\mathrm{gN}$; immune evasion (TAP inhibitor) & envelope \\
\hline UL49 & UL49.5/UL49 & - & - & - & - & - & - & & \\
\hline UL48 & UL48 & - & - & - & - & - & - & $\begin{array}{l}\text { VPI6, } \alpha \text {-TIF; gene regulation(transactivator); } \\
\text { viral egress }\end{array}$ & tegument \\
\hline UL47 & UL48/UL47 & - & - & - & - & 4.0 & 3.9 & & \\
\hline UL46 & UL48/UL47/UL46 & - & - & - & - & - & - & VPII/I2; unknown; tegument protein & \\
\hline GII & UL28/UL27 & - & - & - & - & 6.7 & 6.3 & & \\
\hline ICPI8.5 & UL28 & - & - & - & - & - & 7.4 & $\begin{array}{l}\text { ICPI8,5; DNA cleavage and packaging; } \\
\text { component of the ULI5/UL28 terminase }\end{array}$ & capsid precursor \\
\hline UL29 & UL29 & - & 6.0 & 9.2 & 10.6 & 8.9 & 10.9 & $\begin{array}{l}\text { ICP8; DNA replication and recombination; } \\
\text { binds ssDNA }\end{array}$ & nonstructural \\
\hline UL30 & UL30 & - & - & 4.2 & - & - & - & $\begin{array}{l}\text { DNA replication; DNA polymerase subunit of } \\
\text { UL30/UL } 42 \text { holoenzyme }\end{array}$ & nonstructural \\
\hline UL3I & UL32/UL3I & - & - & - & 4.5 & 9.2 & 10.1 & & \\
\hline UL32 & UL32 & - & - & - & - & 4.0 & 4.1 & $\begin{array}{l}\text { DNA packaging; efficient localization of } \\
\text { capsids to replication compartments }\end{array}$ & capsid precursor \\
\hline UL33 & UL33 & - & - & - & - & 4.5 & 5.8 & $\begin{array}{l}\text { DNA cleavage and packaging; associates with } \\
\text { UL28 and ULI } 5\end{array}$ & nonstructural \\
\hline UL34 & UL33/UL34 & - & - & - & - & 6.1 & 5.0 & & \\
\hline UL35 & UL33/UL34/UL35 & - & - & 5.6 & 7.1 & 9.5 & 9.5 & & \\
\hline UL36I & UL36 & - & - & - & - & - & - & $\begin{array}{l}\text { VPI/2; viral egress(capsid tegumentation); } \\
\text { interacts with UI37 and capsid }\end{array}$ & tegument \\
\hline UL362 & UL36 & - & - & - & - & - & 3.8 & $\begin{array}{l}\text { VPI/2; viral egress(capsid tegumentation); } \\
\text { interacts with UI37 and capsid }\end{array}$ & tegument \\
\hline UL37 & UL37maj/UL37min & - & - & - & - & - & 5.0 & & \\
\hline UL38 & UL38 & - & - & - & - & - & - & $\begin{array}{l}\text { VPI9c; minor capsid protein; UL38/ULI8/ } \\
\text { ULI8 triplex component }\end{array}$ & capsid \\
\hline UL39 & UL39 & - & - & - & - & 4.4 & 6.3 & $\begin{array}{l}\text { nucleotide synthesis; large subunit of } \\
\text { ribonucleotide reductase }\end{array}$ & nonstructural \\
\hline UL40 & UL39/UL40 & - & - & - & - & - & - & & \\
\hline UL4I & UL4I & - & - & - & - & 4.2 & 6.8 & $\begin{array}{l}\text { VHS, gene regulation; Rnase, degrades host } \\
\text { and viral mRNAs }\end{array}$ & tegument \\
\hline UL42 & UL42 & - & - & - & 6.3 & 6.9 & 4.6 & $\begin{array}{l}\text { DNA replication; polymerase accessory } \\
\text { subunit of UL30/UL42 holoenzyme }\end{array}$ & nonstructural \\
\hline UL43 & UL43 & - & - & - & - & 4.1 & 6.2 & $\begin{array}{l}\text { inhibits glycoprotein-mediated membrane } \\
\text { fusion; type III membrane protein }\end{array}$ & envelope \\
\hline GIIINIA3 & UL44 & - & - & - & 8.2 & 12.7 & 13.9 & $\begin{array}{l}\text { gC; viral entry (virion attachment); type I } \\
\text { membrane protein }\end{array}$ & envelope \\
\hline ORF2NIA3 & UL24/UL25/UL26/UL26.5 & - & - & - & - & - & - & & \\
\hline UL26NIA3 & UL24/UL25/UL26 & - & - & - & 6.7 & 8.3 & 7.6 & & \\
\hline ORFINIA3 & UL24/UL25 & & & & & 8.1 & 8.0 & & \\
\hline UL25NIA3 & UL24/UL25 & - & - & - & 8.3 & 10.7 & 12.2 & & \\
\hline UL24NIA3 & UL24 & - & - & - & 6.9 & 9.8 & 10.4 & unknown, type III membrane protein & unknown \\
\hline TKNIA3 & UL23 & - & - & - & - & 5.0 & 6.8 & $\begin{array}{l}\text { TK, nucleotide synthesis; thymidine kinase; } \\
\text { selectively activates acyclovir }\end{array}$ & nonstructural \\
\hline GHNIA3 & UL22 & - & - & 4.8 & 6.0 & 8.8 & 9.0 & $\begin{array}{l}\text { gH; viral entry (fusion); cell-cell spread; type i } \\
\text { membrane PT }\end{array}$ & envelope \\
\hline UL2INIA3 & UL2I & - & - & - & - & 5.9 & 5.5 & $\begin{array}{l}\text { unknown; capsid-associated tegument } \\
\text { protein; interacts with ULI6 }\end{array}$ & tegument \\
\hline UL20NIA3 & UL20 & - & - & - & 3.8 & 5.3 & 7.3 & viral egress, type III membrane protein & unknown \\
\hline ULI9I & ULI9maj/ULI9min & - & - & - & 5.0 & 9.7 & 10.8 & & \\
\hline ULI92 & ULI $9 \mathrm{maj} / \mathrm{UL} 19 \mathrm{~min}$ & - & - & 6.6 & 8.6 & 12.6 & 12.9 & & \\
\hline
\end{tabular}


Table 2: Viral probes and fold-change during infection kinetics. (Continued)

\begin{tabular}{|c|c|c|c|c|c|c|c|c|c|}
\hline ULI8 & Ul19min/ULI8 & - & - & - & 7.0 & 5.7 & 9.6 & & \\
\hline ULI5EX2 & ULI 5 ( $2^{\text {nd }}$ exon $)$ & - & - & 6.4 & 6.5 & 7.5 & 9.2 & $\begin{array}{l}\text { DNA cleavage/encapsidation; terminase } \\
\text { subunit of ULI5/UL28 terminase6 }\end{array}$ & capsid precursor \\
\hline ULI7 & ULI7 & - & - & - & - & - & - & DNA cleavage and encapsidation & inner capsid \\
\hline ULI6 & ULI7/UII6 & - & - & - & 4.5 & 6.2 & 5.0 & & \\
\hline ULI5EXI2 & ULI5 ( ${ }^{\text {st }}$ exon $)$ & - & - & - & - & 4.0 & 7.7 & $\begin{array}{l}\text { DNA cleavage/encapsidation; terminase } \\
\text { subunit of ULI5/UL28 terminaseUL6 }\end{array}$ & capsid precursor \\
\hline ULI4 & ULI4 & & & & 6.1 & 6.1 & 9.8 & unknown & unknown \\
\hline ULI42 & ULI4 & - & - & - & - & 6.3 & 7.8 & unknown & unknown \\
\hline ULI3 & ULI4/ULI3 & - & - & - & - & - & - & & \\
\hline ULI2 & ULI4/ULI3/ULI2 & - & - & - & - & 3.7 & 5.3 & & \\
\hline ULII & ULI4/ULI3/ULI2/ULI I & - & - & - & - & - & 6.0 & & \\
\hline ULIO & ULI0 & - & - & - & - & 6.6 & 6.1 & $\begin{array}{l}\text { gM; inhibits glycoprotein-mediated membrane } \\
\text { fusion; type III membrane protein }\end{array}$ & envelope \\
\hline UL92 & UL9 & - & - & - & - & - & 4.1 & not found & non structural \\
\hline UL8.5 & UL9/UL8.5 & - & - & - & 4.0 & - & - & & \\
\hline UL8 & UL9/UL8.5/UL8 & - & - & - & - & - & - & & \\
\hline UL7 & UL6/UL7 & - & - & 5.0 & 7.4 & 10.7 & 9.4 & & \\
\hline UL6 & UL6 & - & - & 5.0 & 12.7 & 13.8 & 13.3 & $\begin{array}{l}\text { capsid protein; portal protein; docking site for } \\
\text { terminase }\end{array}$ & capsid \\
\hline UL5 & UL5 & - & - & 4.3 & 6.3 & 8.7 & 5.9 & $\begin{array}{l}\text { DNA replication; part of UL5/UL8/UL52 } \\
\text { helicase/primase complex }\end{array}$ & nonstructural \\
\hline UL4 & UL5/UL4 & - & - & - & - & 3.5 & 5.5 & unknown & \\
\hline UL3.5 & ULI/UL2/UL3/UL3.5 & - & - & - & - & - & - & & \\
\hline UL3 & ULI/UL2/UL3 & - & - & - & - & 5.1 & 6.5 & & \\
\hline UL2 & ULI/UL2 & - & - & - & 4.2 & 5.4 & 5.4 & & \\
\hline ULI & ULI & - & - & - & - & 6.5 & 7.3 & gL; viral entry (fusion); sell-sell spread & envelope \\
\hline LLTEI & 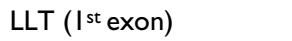 & - & - & - & 4.6 & 6.5 & 8.0 & not found & unknown \\
\hline EP02 & EPO/LLT & - & - & - & - & - & - & & \\
\hline EPOI & EPO/LLT & - & - & - & - & 6.3 & 4.7 & & \\
\hline LLTI2 & LLT intron & - & - & - & - & 3.7 & 4.7 & & \\
\hline LLTE2। & LLT (2nd exon) & - & - & - & - & - & - & not found & unknown \\
\hline IEP2 & IEI 80 & - & - & - & 3.5 & - & - & $\begin{array}{l}\text { ICP4; gene regulation (transactivator); } \\
\text { immediate early protein }\end{array}$ & nonstructural \\
\hline IEPI & IEI 80 & - & - & - & - & - & - & $\begin{array}{l}\text { ICP4; gene regulation (transactivator); } \\
\text { immediate early protein }\end{array}$ & nonstructural \\
\hline $\mathrm{Ba} 5$ & IEI80/LLT (2 $2^{\text {nd }}$ exon $)$ & & & & 5.9 & 6.7 & 4.3 & & \\
\hline LLTE222 & LLT (2nd exon) & - & - & - & 6.8 & 8.9 & 8.2 & not found & unknown \\
\hline RSP40 & USI & - & 5.3 & 8.3 & 12.9 & 15.3 & 13.0 & $\begin{array}{l}\text { RSP40/ICP22; unknown; HIV-I homolog acts } \\
\text { as regulator of gene expression }\end{array}$ & nonstructural \\
\hline PKNIA3 & US3maj/US3min & - & - & - & - & 6.0 & 5.0 & $\begin{array}{l}\text { PK, minor and major form of protein kinase; } \\
\text { inhibits apoptosis }\end{array}$ & tegument \\
\hline GXGG & US3maj/US3min/US4 & - & - & 6.5 & 9.1 & 10.6 & 11.0 & & \\
\hline GP50GD & US6 & - & - & - & - & - & - & gD; viral entry, type I membrane protein & envelope \\
\hline GP63GI & US6/US7 & - & - & - & 5.0 & 6.3 & 8.5 & & \\
\hline GIGE & US8 & - & - & - & 4.0 & - & 4.3 & gE; cell-cell spread & envelope \\
\hline $11 K 2$ & US9/US8 & - & - & - & 9.0 & 10.0 & 10.4 & & \\
\hline $28 \mathrm{KNIA} 3$ & US2 & - & - & - & 6.2 & 6.9 & 7.1 & $\begin{array}{l}28 \mathrm{~K} \text {, tegument protein; membrane associated } \\
\text { protein }\end{array}$ & tegument \\
\hline
\end{tabular}

*gene function and structural role [I] are only specified for amplicons that hybridize to a single transcript.

- gene not found differentially expressed between PrV infected and mock-infected cells

\section{Immune response, apoptosis, nucleic acid binding and actin cytoskeleton pathways are modulated during PrV infection}

Among all the biological processes (Table 3) and top functions (Table 4), shown to be regulated during PrV infection, we examined in greater detail genes differentially expressed in four pathways i.e. immune response, apoptosis, nucleic acid binding and actin cytoskeleton (Table 5).
For genes involved in immune response, we observed that CD 4 and CD69 were up- and down-regulated from $4 \mathrm{~h} \mathrm{pi,}$ respectively (Table 5) and that several chemokine ligand and interleukin genes such as IL12A, IL12B and IL17 were down-regulated at 4 and $8 \mathrm{~h}$ pi. These observations have a poor biological significance. Since the relevant gene products are known to be specific of immune cells, it is probable that these transcript expressions are not correlated 


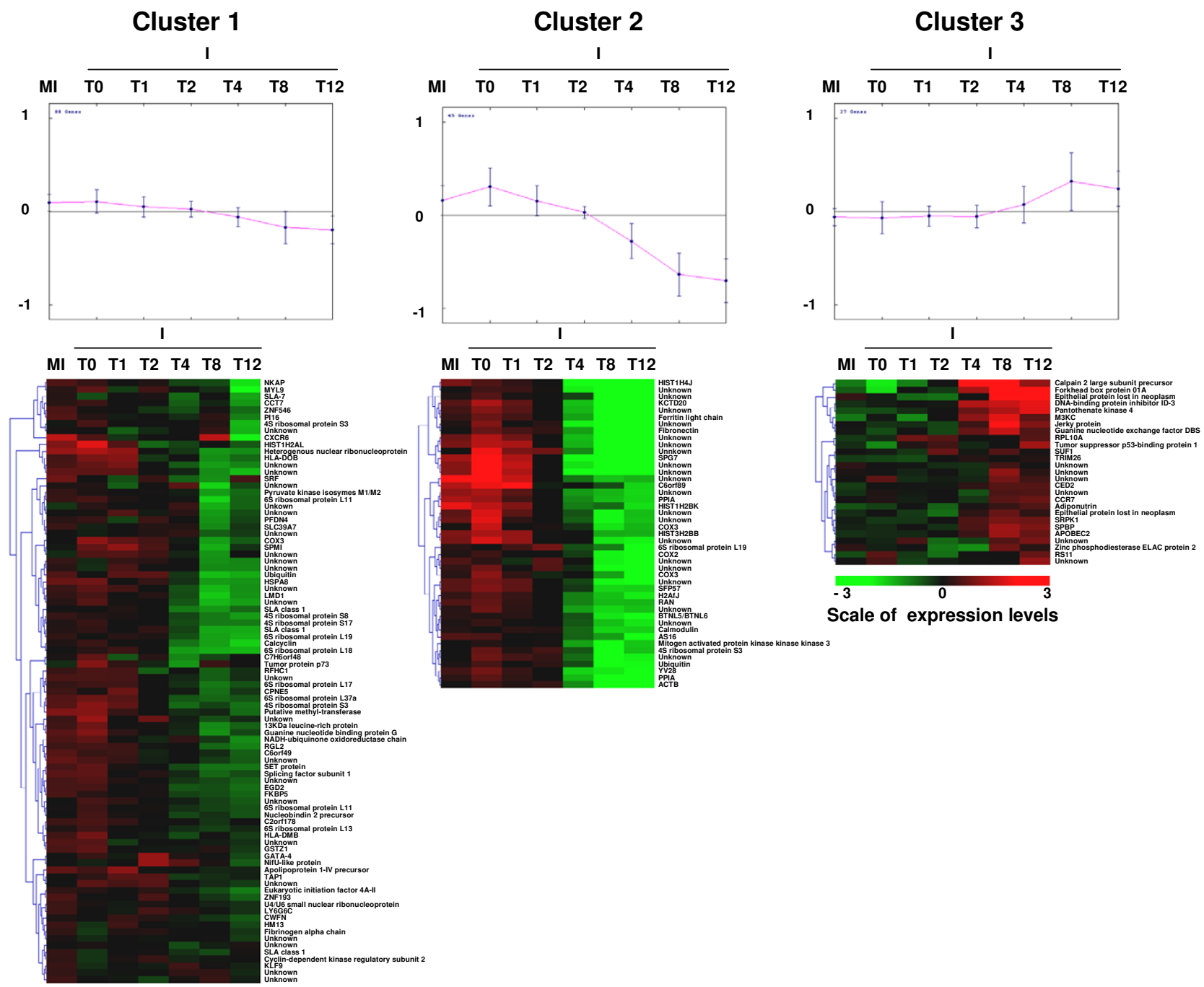

\section{Figure 4}

Clusters of PKI 5 gene expression levels identified by the k-means method. The expression levels of genes that are differentially expressed between infected and mock-infected cells at each time point are analyzed by the k-means method (three clusters). Averages of normalized intensities for all mock-infected conditions and for each infected condition were centered (median) by genes. For each cluster, one graph and one clustering picture are represented. The graph shows the mean of the expression levels of all genes $(x=$ Time; $y=$ mean of levels of expression) and the clustering picture depicts the mean of each gene expression level for all mock-infected time points and for each infected time point $(x=$ Time; $y=$ level of expression).

with significant protein synthesis in the present epithelial cell context. Among the genes involved in interferonmediated immunity, many were modulated during $\operatorname{PrV}$ infection (Table 5) i.e. IFNAR2 and IFI6 transcript levels increased from $4 \mathrm{~h}$ pi and ISGF3G transcript levels at $8 \mathrm{~h}$ pi. The expression of IRF1, IRF2and IRF5 appeared downregulated from $4 \mathrm{~h}$ pi and that of IRF3 at $8 \mathrm{~h}$ pi. IFNA6, IFI30 were down-regulated $8 \mathrm{~h}$ pi while IFNG, which was included in the SLA/PrV probe set, was not detected as a differentially expressed gene. In addition, the expression of TLR8, involved in recognition of viral nucleic acid binding was decreased at $8 \mathrm{~h}$ pi. Immunophilin genes were also regulated during infection. From 4 h pi PPIA (alias Cyclophilin A) was down-regulated (Table 5) and at $8 \mathrm{~h}$ pi PPIF and PPIG were down-regulated while PPIH was up-regulated. 
Table 3: Biological processes associated with differentially expressed cellular genes.

\begin{tabular}{|c|c|c|c|c|}
\hline \multirow[t]{2}{*}{ Biological process* } & \multicolumn{4}{|c|}{ Time pi $(h)^{\S}$} \\
\hline & TI & $\mathrm{T} 2$ & T4 & T8 \\
\hline Protein metabolism and modification (BP00060) & 1 & 26 & 311 & 768 \\
\hline Nucleoside, nucleotide and nucleic acid metabolism (BP0003I) & 3 & 22 & 321 & 702 \\
\hline Developmental processes (BP00193) & 8 & 16 & 224 & 487 \\
\hline Signal transduction (BPOOIO2) & 5 & 14 & 337 & 737 \\
\hline Transport (BP00I4I) & I & 13 & 139 & 308 \\
\hline Cell cycle (BP00203) & 2 & 12 & 124 & 262 \\
\hline Immunity and defense (BP00I48) & i & 11 & 120 & 309 \\
\hline Intracellular protein traffic (BPOOI25) & 2 & 10 & 115 & 266 \\
\hline Cell structure and motility (BP00285) & 2 & 7 & 119 & 279 \\
\hline Cell proliferation and differentiation (BP00224) & 2 & 6 & 100 & 215 \\
\hline Other metabolism (BP00289) & 2 & 6 & 71 & 159 \\
\hline Apoptosis (BP00I79) & 0 & 6 & 61 & 132 \\
\hline Cell adhesion (BPOOI24) & 0 & 5 & 68 & 136 \\
\hline Carbohydrate metabolism (BP0000I) & 0 & 3 & 67 & 165 \\
\hline Amino acid metabolism (BPO00I3) & 1 & 3 & 36 & 70 \\
\hline Protein targeting and localization (BP00I37) & 1 & 3 & 25 & 65 \\
\hline Blood circulation and gas exchange (BP00209) & 0 & 3 & 9 & 26 \\
\hline Oncogenesis (BP0028I) & 0 & 2 & 57 & 116 \\
\hline Neuronal activities (BP00I66) & I & 2 & 50 & 106 \\
\hline Lipid, fatty acid and steroid metabolism (BP00019) & 0 & I & 71 & 183 \\
\hline Electron transport (BP00076) & 0 & 1 & 32 & 69 \\
\hline Muscle contraction (BP00I73) & 0 & i & 26 & 55 \\
\hline Sensory perception (BP00I82) & 0 & I & 25 & 60 \\
\hline Coenzyme and prosthetic group metabolism (BP0008I) & 0 & I & 19 & 46 \\
\hline Miscellaneous (BP002II) & 0 & 1 & 12 & 30 \\
\hline Phosphate metabolism (BP00095) & 0 & I & 8 & 27 \\
\hline Sulfur metabolism (BPOOIOI) & 0 & 1 & 8 & 22 \\
\hline Nitrogen metabolism (BP00090) & 0 & I & 5 & 5 \\
\hline Non-vertebrate process (BP0030I) & 0 & 0 & 1 & 3 \\
\hline Homeostasis (BP00267) & 0 & 0 & 16 & 49 \\
\hline Biological process unclassified (BP00216) & 7 & 40 & 549 & 1232 \\
\hline Number of analyzed genes & 24 & $|4|$ & 1272 & 4458 \\
\hline
\end{tabular}

$\S$ The number of genes from the Qiagen_NRSP8 microarray found in Panther database is reported at each time point for each biological process.

*The same focus gene may exist in different biological processes.

For the apoptosis pathway, genes belonging to the BCL-2 molecule family, FAIM2, CASP1 and CASP3 were downregulated whereas CASP7 and NF-KB2 were up-regulated. Transcript levels of JAK1, XBP1, ATF4 and HSPA5 were decreased at $8 \mathrm{~h}$ pi. HSPA1A, HSPA1B, HSPA2, HSPA4, HSPA4K and HSPA8 were up-regulated at $8 \mathrm{~h}$ pi and EIF2A from $4 \mathrm{~h}$ pi. HSPA6 was first down-regulated at $2 \mathrm{~h}$ pi and then up-regulated from $4 \mathrm{~h}$ pi. Several differentially expressed genes, which belong to the apoptosis pathway, were also involved in the stress response.

Among the differentially expressed genes that play a role in nucleoside, nucleotide and nucleic acid binding, the expression of histone genes HIST1H2AL, HIST1H4J, HIST1H2BK was decreased from $4 \mathrm{~h}$ pi. Expression of several histone deacetylases was also regulated during infection: HDAC2 and HDAC10 expression levels increased, while HDAC3, HDAC6, and HDAC9 expression decreased. HDAC2 and HDAC9 were regulated early from $2 \mathrm{~h}$ pi. Several genes encoding signal transducers and activators of transcription (STAT1, STAT3, STAT5B and STAT6) were down-regulated during PrV infection.

Within the actin cytoskeleton pathway, ACTG1 was upregulated very early i.e. as soon as $1 \mathrm{~h}$ pi. Other genes such as ACTC1, ACTRT2, ACTA4, MYO1D and MYO5A were all down-regulated from 4 or $8 \mathrm{~h}$ pi and ACTL6A was up-regulated at $8 \mathrm{~h}$ pi.

\section{Validation of microarray results by quantitative real-time PCR (qRT-PCR)}

Five genes involved in the presentation antigen class I pathway were studied by qRT-PCR: SLA Ia, TAP1, TAP2, PSMB8 and PSMB9. PPIA, down-regulated during infec- 
Table 4: Top functions associated with significant networks identified by IPA and number of focus genes at each time point.

\begin{tabular}{|c|c|c|c|c|}
\hline \multirow[t]{2}{*}{ Top functions } & \multicolumn{4}{|c|}{ Time } \\
\hline & TI & $\mathrm{T} 2$ & $\mathrm{~T} 4$ & T8 \\
\hline Gene Expression & 9 & 12 & 178 & 297 \\
\hline Molecular Transport & 9 & - & 81 & 372 \\
\hline Drug Metabolism & 9 & - & 31 & 83 \\
\hline Cancer & - & 47 & 386 & 357 \\
\hline Connective Tissue Development and Function & - & 27 & 103 & 152 \\
\hline Cell Cycle & - & 24 & 246 & 432 \\
\hline Cellular Development & - & 23 & 144 & 64 \\
\hline Cell Death & - & 23 & $14 \mid$ & 205 \\
\hline Cell Morphology & - & 23 & 91 & 58 \\
\hline Cellular Movement & - & 15 & 92 & 125 \\
\hline Cellular Assembly and Organization & - & 15 & 82 & 358 \\
\hline Post-Translational Modification & - & 13 & 75 & 79 \\
\hline Small Molecule Biochemistry & - & 13 & 64 & 324 \\
\hline Amino Acid Metabolism & - & 13 & 56 & 219 \\
\hline Neurological Disease & - & 12 & 59 & 147 \\
\hline Organismal Injury and Abnormalities & - & 12 & 30 & 56 \\
\hline Cellular Growth and Proliferation & - & 11 & 93 & 114 \\
\hline Connective Tissue Disorders & - & 11 & 15 & 21 \\
\hline Cell Signaling & - & - & 223 & 662 \\
\hline DNA Replication Recombination and Repair & - & - & 183 & 194 \\
\hline Genetic Disorder & - & - & 128 & 218 \\
\hline Nervous System Development and Function & - & - & 98 & 166 \\
\hline Hematological Disease & - & - & 92 & 89 \\
\hline Protein Synthesis & - & - & 88 & 204 \\
\hline Dermatological Diseases and Conditions & - & - & 82 & 175 \\
\hline Hematological System Development and Function & - & - & 81 & 116 \\
\hline Lipid Metabolism & - & - & 79 & 363 \\
\hline Cell-To-Cell Signaling and Interaction & - & - & 76 & 122 \\
\hline Skeletal and Muscular Disorders & - & - & 76 & 33 \\
\hline Immune Response & - & - & 71 & 246 \\
\hline Cardiovascular Disease & - & - & 70 & 80 \\
\hline Cellular Function and Maintenance & - & - & 61 & 263 \\
\hline Embryonic Development & - & - & 54 & 180 \\
\hline Endocrine System Development and Function & - & - & 53 & 62 \\
\hline Immunological Disease & - & - & 44 & 54 \\
\hline RNA Post-Transcriptional Modification & - & - & 43 & 122 \\
\hline Nucleic Acid Metabolism & - & - & 39 & 130 \\
\hline Reproductive System Development and Function & - & - & 35 & 26 \\
\hline Tissue Development & - & - & 34 & 73 \\
\hline Protein Trafficking & - & - & 34 & 63 \\
\hline Protein Folding & - & - & 32 & 31 \\
\hline Carbohydrate Metabolism & - & - & 31 & 136 \\
\hline Cardiovascular System Development and Function & - & - & 31 & 127 \\
\hline Organismal Development & - & - & 29 & 30 \\
\hline Cellular Compromise & - & - & 28 & 96 \\
\hline Organ Morphology & - & - & 28 & 91 \\
\hline Vitamin and Mineral Metabolism & - & - & 27 & 61 \\
\hline Skeletal and Muscular System Development and Function & - & - & 25 & 33 \\
\hline Developmental Disorder & - & - & 18 & 33 \\
\hline Inflammatory Disease & - & - & 16 & 95 \\
\hline Nutritional Disease & - & - & 16 & 30 \\
\hline Infectious Disease & - & - & 14 & 65 \\
\hline Metabolic Disease & - & - & 12 & 89 \\
\hline Viral Function & - & - & 61 & - \\
\hline Reproductive System Disease & - & - & 48 & - \\
\hline Ophthalmic Disease & - & - & 32 & - \\
\hline
\end{tabular}


Table 4: Top functions associated with significant networks identified by IPA and number of focus genes at each time point. (Continued)

\begin{tabular}{|c|c|c|c|c|}
\hline Hair and Skin Development and Function & - & - & 31 & - \\
\hline Organ Development & - & - & 31 & - \\
\hline Cardiac Fibrosis & - & - & 30 & - \\
\hline Viral Infection & - & - & 30 & - \\
\hline Cardiac Enlargement & - & - & 28 & - \\
\hline DNA Replication & - & - & 20 & - \\
\hline Cardiac Pulmonary Embolism & - & - & 17 & - \\
\hline Dermatological Diseases and Condition & - & - & 17 & - \\
\hline Cardiac Necrosis/Cell Death & - & - & 16 & - \\
\hline Digestive System Development and Function & - & - & 16 & - \\
\hline Hepatic System Disease & - & - & 14 & - \\
\hline Tumor Morphology & - & - & 13 & - \\
\hline Protein Degradation & - & - & - & 119 \\
\hline Energy Production & - & - & - & 84 \\
\hline Gastrointestinal Disease & - & - & - & 65 \\
\hline Behavior & - & - & - & 61 \\
\hline Immune and Lymphatic System Development and Function & - & - & - & 61 \\
\hline Renal Necrosis/Cell Death & - & - & - & 33 \\
\hline Renal and Urological System Development and Function & - & - & - & 32 \\
\hline Endocrine System Disorders & - & - & - & 31 \\
\hline Cardiac Hypertrophy & - & - & - & 30 \\
\hline Organismal Survival & - & - & - & 28 \\
\hline Free Radical Scavenging & - & - & - & 27 \\
\hline Respiratory System Development and Function & - & - & - & 25 \\
\hline Tissue Morphology & - & - & - & 23 \\
\hline Hepatic System Development and Function & - & - & - & 21 \\
\hline Focus genes & 12 & 98 & 1474 & 2887 \\
\hline
\end{tabular}

*The same focus gene may exist in different top functions.

$\S$ The number of focus genes from the Qiagen_NRSP8 microarray is reported at each time point for each top function.

tion, and TNF, even if not detected as differentially expressed in our transcriptome experiment, were also chosen for validation (Table 6). qRT-PCR were performed for a subset of conditions at $0,2,4,8$, and $12 \mathrm{~h}$ pi (see materials and methods). We confirmed that SLA Ia genes were down-regulated during infection from $8 \mathrm{~h}$ pi. We also observed a clear down-regulation of TAP1 and TAP2 from 8 and $4 \mathrm{~h}$ pi, respectively. An early down-regulation of PSMB8 and PSMB9 was detected before $2 \mathrm{~h}$ pi. TNF was strongly up-regulated from $4 \mathrm{~h}$ pi and PPIA was down-regulated from $2 \mathrm{~h}$ pi.

\section{Cell surface expression of MHC class I and MHC class II molecules on PKI5 cells during PrV infection}

Since our experiments, as well as other studies [6,7], have clearly indicated a down-regulation of the MHC class I genes during PrV infection, we checked, by flow cytometry, for a down-regulation of surface MHC class I molecules on PrV infected PK15 cells at 8 h pi. To visualize infected cells, we used, in the same experimental conditions, a recombinant PrV strain (derived from NIA3) expressing the green fluorescent protein (GFP). Ninety percent of the cells appeared infected and $73 \%$ of these infected cells expressed surface MHC class I molecules on their surface while $89.1 \%$ and $83.9 \%$ of the mock-infected cells expressed MHC class I molecules at 0 and $8 \mathrm{~h}$ pi, respectively (data not shown). The MHC class I mean fluorescence intensity of infected cells at $8 \mathrm{~h}$ pi was $50.9 \%$ of that of mock-infected cells (mean of three experiments) thus confirming a clear decrease of MHC class I molecules expression on the surface of infected cells (Figure 5). As a control, we observed that the expression of tubulin, detected by Western blot, remains unchanged even $8 \mathrm{~h}$ pi in PK15 cells (data not shown).

Since a significant variation in MHC class II transcript levels during infection was detected in our transcriptome analysis, we also analyzed the expression of MHC class II molecules on the surface of PK15 cells. Our results show that $5.5 \%$ of mock-infected cells (at 0 and $8 \mathrm{~h} \mathrm{pi)} \mathrm{and}$ infected cells ( $0 \mathrm{~h}$ pi) expressed surface MHC class II molecules. However, we could not detect any differential expression between infected and mock-infected cells at 8 h pi.

\section{Discussion}

A joint PrV-porcine epithelial cell transcriptomic approach This work is the first study of PrV transcriptome expression during the time course of infection. Moreover, it is the first time that the gene expressions of both PrV (NIA3 strain) and porcine cells during infection are analyzed simultaneously and we demonstrate that virus and host 
Table 5: Subset of differentially expressed cellular genes at each time point.

\begin{tabular}{|c|c|c|c|c|c|c|c|c|c|c|}
\hline \multirow[t]{2}{*}{ Pathway or function } & \multirow[t]{2}{*}{ Clone or oligo name } & \multirow[t]{2}{*}{ Gene symbol } & \multirow[t]{2}{*}{ Human refseq } & \multicolumn{6}{|c|}{ Fold change } & \multirow[t]{2}{*}{ Microarray } \\
\hline & & & & TO & TI & T2 & T4 & T8 & TI2 & \\
\hline \multirow[t]{11}{*}{ Class I antigenic Pathway } & SS00013127 & HLA-A & NM_0021I6 & NS & - & - & - & -4.6 & NS & Qiagen-NRSP8 \\
\hline & SS00001303 & HLA-A & NM_002116 & NS & - & - & - & -3.8 & NS & Qiagen-NRSP8 \\
\hline & SCAN0007.0.20 & SLA la & NM_002II6 & - & - & - & -4.9 & -4.6 & -4.5 & SLA/PRV \\
\hline & SCAN0032.G.07 & SLA la & NM_002II6 & - & - & - & - & -4.0 & - & SLA/PRV \\
\hline & SCANO0I0.J.21 & SLA la & NM_002116 & - & - & - & - & - & -5.9 & SLA/PRV \\
\hline & SCAA0099.0.04 & SLA-7 & NM_0021I6 & - & - & - & -3.5 & -3.6 & - & SLA/PRV \\
\hline & SS00000703 & PSMB8 & NM_148919 & NS & - & - & 5.5 & 7.8 & NS & Qiagen-NRSP8 \\
\hline & SCAC0037.0.09 & TAPI & NM_000593 & - & - & - & - & 3.9 & - & SLA/PRV \\
\hline & SS00010012 & TAPI & NM_000593 & & - & - & - & -7.8 & NS & Qiagen-NRSP8 \\
\hline & SS00002173 & TAP2 & NM_000544 & NS & - & - & -6.9 & - & NS & Qiagen-NRSP8 \\
\hline & SS00010176 & MICB & NM_00593I & NS & - & - & II.I & 11.3 & NS & Qiagen-NRSP8 \\
\hline \multirow{6}{*}{$\begin{array}{c}\text { Class II antigenic } \\
\text { pathway }\end{array}$} & SS00000697 & HLA-DMB & NM_0021I8 & NS & - & - & - & -7.7 & NS & Qiagen-NRSP8 \\
\hline & SS0000066I & HLA-DOA & NM_002II9 & NS & - & - & - & 5.2 & NS & Qiagen-NRSP8 \\
\hline & SS00000973 & HLA-DQAI & NM_002I 22 & NS & - & - & - & 5.2 & NS & Qiagen-NRSP8 \\
\hline & SCABOI37.B. 15 & HLA-DOB & NM_002I 20 & - & - & - & -4.0 & - & - & SLA/PRV \\
\hline & SCAC0044.H.08 & HLA-DMB & NM_002II8 & - & - & - & -4.6 & - & - & SLA/PRV \\
\hline & SS00000824 & CIITA & NM_000246 & NS & - & - & - & 3.3 & NS & Qiagen-NRSP8 \\
\hline \multirow[t]{28}{*}{ Immunity (other genes) } & SS00010182 & CD4 & NM_000616 & NS & - & 5.1 & 14.6 & 14.1 & NS & Qiagen-NRSP8 \\
\hline & SS00009986 & CD69 & NM_00I78I & NS & - & - & -3.1 & -5.9 & NS & Qiagen-NRSP8 \\
\hline & SS00006217 & CLEC2L & XM_498242 & NS & - & 3.2 & 11.8 & 16.1 & NS & Qiagen-NRSP8 \\
\hline & SS00009653 & CLEC5A & NM_0I3252 & NS & - & - & -4.0 & -6.9 & NS & Qiagen-NRSP8 \\
\hline & SS00002913 & IK & NM_006083 & NS & - & - & - & 5.0 & NS & Qiagen-NRSP8 \\
\hline & SS00010183 & ICAMI & NM_00020I & NS & - & - & -4.2 & -9.2 & NS & Qiagen-NRSP8 \\
\hline & SS00003797 & IFNAR2 & NM_207585 & NS & - & - & 3.5 & 7.9 & NS & Qiagen-NRSP8 \\
\hline & SS000I0797 & IFNGR2 & NM_005534 & NS & - & - & - & -6.1 & NS & Qiagen-NRSP8 \\
\hline & SS00002396 & IRFI & NM_002198 & NS & - & - & -5.0 & -9.3 & NS & Qiagen-NRSP8 \\
\hline & SS00009562 & IRF2 & NM_002199 & NS & - & - & -4.4 & -10.8 & NS & Qiagen-NRSP8 \\
\hline & SS00000183 & IRF3 & NM_00I57I & NS & - & - & - & -3.9 & NS & Qiagen-NRSP8 \\
\hline & SS00003318 & IRF5 & NM_032643 & NS & - & - & -3.5 & -7.9 & NS & Qiagen-NRSP8 \\
\hline & SS00000904 & IFNA6 & NM_021002 & NS & - & - & - & -7.2 & NS & Qiagen-NRSP8 \\
\hline & SS00010817 & IFI6 & NM_002038 & NS & - & - & 6.5 & 12.5 & NS & Qiagen-NRSP8 \\
\hline & SS000I08II & IFI30 & NM_006332 & NS & - & - & - & -6.1 & NS & Qiagen-NRSP8 \\
\hline & SS00001608 & ISGF3G & NM_006084 & NS & - & - & - & 3.9 & NS & Qiagen-NRSP8 \\
\hline & SS00009843 & ILI2A & NM_000882 & NS & - & - & -3.3 & -17.1 & NS & Qiagen-NRSP8 \\
\hline & SS0000984I & ILI 2B & NM_002187 & NS & - & - & -7.9 & -17.1 & NS & Qiagen-NRSP8 \\
\hline & SS0000802I & TLR8 & NM_016610 & NS & - & - & -4.6 & -5.9 & NS & Qiagen-NRSP8 \\
\hline & SCAA00I5.B.22 & PPIA & NM_02II30.3 & - & - & - & -3.9 & -4.8 & -4.8 & SLA/PRV \\
\hline & SCAU000I.B.05 & PPIA & NM_02II30.3 & - & - & - & -3.6 & -4.3 & -4.7 & SLA/PRV \\
\hline & SS00003892 & PPILI & NM_0I6059 & NS & - & - & - & 3.2 & NS & Qiagen-NRSP8 \\
\hline & SS00001759 & PPIL2 & NM_I48I76 & NS & - & - & - & 4.1 & NS & Qiagen-NRSP8 \\
\hline & SS0000II78 & PPIF & NM_005729 & NS & - & - & - & -3.8 & NS & Qiagen-NRSP8 \\
\hline & SS0000I24I & PPIG & NM_004792 & NS & - & - & - & -4.3 & NS & Qiagen-NRSP8 \\
\hline & SS00005782 & PPIH & NM_006347 & NS & - & - & - & 5.1 & NS & Qiagen-NRSP8 \\
\hline & SS00006083 & FKBP3 & NM_002013 & NS & - & - & - & -8.3 & NS & Qiagen-NRSP8 \\
\hline & SS00002702 & FKBP4 & NM_002014 & NS & - & 3.6 & 13.0 & 14.3 & NS & Qiagen-NRSP8 \\
\hline \multirow[t]{7}{*}{ Apoptosis } & SS00003686 & BNIPI & NM_00I 205 & NS & - & - & - & -6.1 & NS & Qiagen-NRSP8 \\
\hline & SS00000546 & BAKI & NM_00II88 & NS & - & - & - & -4.3 & NS & Qiagen-NRSP8 \\
\hline & SS000I0935 & BCLAFI & NM_0I4739 & NS & - & -4.0 & -4.6 & -6.6 & NS & Qiagen-NRSP8 \\
\hline & SS0000III50 & BCL2LI & NM_I38578 & NS & - & - & -3.4 & -6.5 & NS & Qiagen-NRSP8 \\
\hline & SS00005026 & BCL2LI4 & NM_I38723 & NS & - & - & - & -5.8 & NS & Qiagen-NRSP8 \\
\hline & SS00000872 & CASPI & NM_033293 & NS & - & - & 3.6 & 5.0 & NS & Qiagen-NRSP8 \\
\hline & SS00000520 & CASP3 & NM_03299I & NS & - & - & - & -0.7 & NS & Qiagen-NRSP8 \\
\hline
\end{tabular}


Table 5: Subset of differentially expressed cellular genes at each time point. (Continued)

\begin{tabular}{|c|c|c|c|c|c|c|c|c|c|c|}
\hline & SS00004783 & CASP7 & NM_00I227 & NS & - & - & - & 6.7 & NS & Qiagen-NRSP8 \\
\hline & SS000003624 & CARD6 & NM_032587 & NS & - & - & 3.5 & 6.6 & NS & Qiagen-NRSP8 \\
\hline & SS0000056I & DDX58 & NM_014314 & NS & - & -3.1 & -4.3 & -8.3 & NS & Qiagen-NRSP8 \\
\hline & SS00000329 & FAFI & NM_00705I & NS & - & - & - & 5.8 & NS & Qiagen-NRSP8 \\
\hline & SS000I2494 & FAIM2 & NM_0I 2306 & NS & - & - & -4.6 & -10.7 & NS & Qiagen-NRSP8 \\
\hline ER* stress & SS00000384 & EIF2A & NM_032025 & NS & - & - & 3.7 & 7.1 & NS & Qiagen-NRSP8 \\
\hline \multirow[t]{3}{*}{ Pathway } & SS00008645 & XBPI & NM_005080 & NS & - & - & - & -6.4 & NS & Qiagen-NRSP8 \\
\hline & SS00004223 & ATF4 & NM_182810 & NS & - & - & - & -4.1 & NS & Qiagen-NRSP8 \\
\hline & SS0000I308 & HSPA8 & NM_006597 & NS & - & - & - & 3.6 & NS & Qiagen-NRSP8 \\
\hline Nucleic acid & SCAB0073.K.18 & HISTIH2BK & NM_080593 & - & - & - & -3.9 & -6.8 & -4.4 & SLA/PRV \\
\hline \multirow[t]{12}{*}{ Binding } & SCAA0I22.E.09 & HISTIH2AL & NM_0035II & - & - & - & -3.9 & -6.0 & -3.7 & SLA/PRV \\
\hline & SCAB0057.M.2I & HISTIH4J & NM_021968 & - & - & - & -5.1 & -4.4 & -4.0 & SLA/PRV \\
\hline & SCAB00I5.G.08 & HIST3H2BB & NM_021968 & - & - & - & - & -4.2 & -5.4 & SLA/PRV \\
\hline & SS00005067 & HDAC2 & NM_00I527 & NS & - & 4.6 & 8.3 & 9.1 & NS & Qiagen-NRSP8 \\
\hline & SS00004784 & HDAC3 & NM_003883 & NS & - & - & -5.5 & -10.9 & NS & Qiagen-NRSP8 \\
\hline & SS00007434 & HDAC6 & NM_006044 & NS & - & - & -3.7 & -8.4 & NS & Qiagen-NRSP8 \\
\hline & SS00003586 & HDAC9 & NM_0I4707 & NS & - & -3.5 & -4.8 & -10.6 & NS & Qiagen-NRSP8 \\
\hline & SS00004682 & HDACIO & NM_032019 & NS & - & - & - & 3.9 & NS & Qiagen-NRSP8 \\
\hline & SS00007084 & STATI & NM_0073I5 & NS & - & - & - & 7.6 & NS & Qiagen-NRSP8 \\
\hline & SS00008286 & STAT3 & NM_139276 & NS & - & - & - & -4.4 & NS & Qiagen-NRSP8 \\
\hline & SS00008435 & STAT5B & NM_0I 2448 & NS & - & - & -5.3 & -9.9 & NS & Qiagen-NRSP8 \\
\hline & SS00004427 & STAT6 & NM_003I53 & NS & - & - & - & -4.6 & NS & Qiagen-NRSP8 \\
\hline \multirow[t]{7}{*}{ Cytoskeleton } & SS00003440 & $\mathrm{ACTCl}$ & NM_005I59 & NS & - & - & - & -8.9 & NS & Qiagen-NRSP8 \\
\hline & $5 S 00013114$ & ACTGI & NM_001614 & NS & 3.3 & 6.9 & 19.4 & 18.2 & NS & Qiagen-NRSP8 \\
\hline & SS00002774 & ACTL6A & NM_00430I & NS & - & - & - & 3.6 & NS & Qiagen-NRSP8 \\
\hline & SS00005476 & ACTRT2 & NM_08043I & NS & - & - & - & -7.2 & NS & Qiagen-NRSP8 \\
\hline & SS0000743I & ACTA4 & NM_00492 & NS & - & - & -3.7 & -3.9 & NS & Qiagen-NRSP8 \\
\hline & SS000II046 & MYOID & NM_015194 & NS & - & - & -4.7 & -10.2 & NS & Qiagen-NRSP8 \\
\hline & SS000078I8 & MYO5A & NM_000259 & NS & - & - & -3.7 & -9.8 & NS & Qiagen-NRSP8 \\
\hline
\end{tabular}

* ER: Endoplasmic Reticulum

NS: Not Studied

-: not differentially express

cell transcriptome modifications can be examined with a unique microarray combining viral and host cell probe sets. Indeed, a majority of transcriptomic studies have focused either on host or on pathogen gene expression profiling $[11,22,23]$ and only a few studies report the simultaneous detection of pathogen and mammalian host transcriptomes i.e. Plasmodium berghei ANKA and mouse [24] and EBV-NK/T cell lymphoma and man [25]. Our work confirms the feasibility and the relevance of this kind of approach to establish a direct link between pathogen and cellular gene expression. In order to explore porcine cellular gene expression with even more detail, we chose to supplement the SLA/PrV microarray with the Qiagen-NRSP8 microarray. The sensitivity of each microarray differed according to the nature of the probes (70mer oligonucleotides versus DNA/cDNA) as shown by comparative studies [26]. Seventy-mer oligonucleotides give better results in terms of specificity and sensitivity compared to cDNA microarrays and this could explain some discrepancies observed between both microarrays in particular for the TAP1 gene [27] as confirmed in our study. With this integrated approach, a parallel increase in the number of differentially expressed $\operatorname{PrV}$ and cellular genes was detected illustrating the viral and cellular transcript modifications during infection.

\section{A picture of PrV gene transcription during PKI5 cell line infection}

In our experimental conditions, we obtain a picture of the global PrV gene transcription during the lytic cycle. PrV transcription was monitored in single cycle conditions using a high MOI that guarantees that more that $90 \%$ cells are infected. Despite the presence of nested transcription units in PrV preventing the design of probes specific of unique transcripts for some genes, we were, however, able to confidently report viral gene expression for probes specific of unique viral transcripts and draw a general picture of $\operatorname{PrV}$ transcription during the time course of infection. As expected, the expression of most viral genes increased during infection. Our results show that a notable increase in transcript levels and in the number of differentially expressed viral probes, detected from $4 \mathrm{~h} \mathrm{pi}$, correlates 
Table 6: Cellular gene expression study by qRT-PCR.

\begin{tabular}{ccccccc}
\hline & \multicolumn{5}{c}{ Change (n-fold) } \\
\cline { 2 - 7 } Gene & MI*_TI2/MI*_T0 & I**_T0/MI*_T0 & I*_T2/MI**_T0 & I**_T4/MI*_T0 & I**_T8/MI*_T0 & I**_TI 2/MI*_T0 \\
\hline TNF & 1.6 & 2.3 & 2.6 & 14.7 & 14.5 & 10.5 \\
PPIA & 1.2 & 1.1 & 0.7 & 0.2 & 0.1 & 0.1 \\
SLA la & 0.7 & 0.9 & - & - & 0.6 & 0.5 \\
TAPI & - & - & - & 0.8 & 0.5 & 0.3 \\
TAP2 & 1.2 & 1.2 & 0.6 & 0.7 & 0.3 & 0.3 \\
PSMB9 & 0.8 & 0.6 & 0.7 & 0.6 & 0.3 & 0.3 \\
PSMB8 & - & 0.6 & & & \\
\hline
\end{tabular}

- - no detected difference between two samples

- *: mock-infected

- **: PrV infected

with viral growth and thus coincides with the beginning of the release of extracellular progeny (see Figure 2, Figure 3 , Table 1 and Table 2). It has already been reported that the beginning of viral progeny usually occurs between 4 and $5 \mathrm{~h}$ pi but without any description of the global viral transcription [1]. We observe a continuous increase in transcript levels and in the number of differentially expressed viral probes between 4 and $8 \mathrm{~h}$ pi followed by a stabilization when virion production is maximum. This suggests that the transcriptional machinery is fully active at $8 \mathrm{~h}$ pi thus permitting a massive virion production. All the different classes of viral transcripts are represented

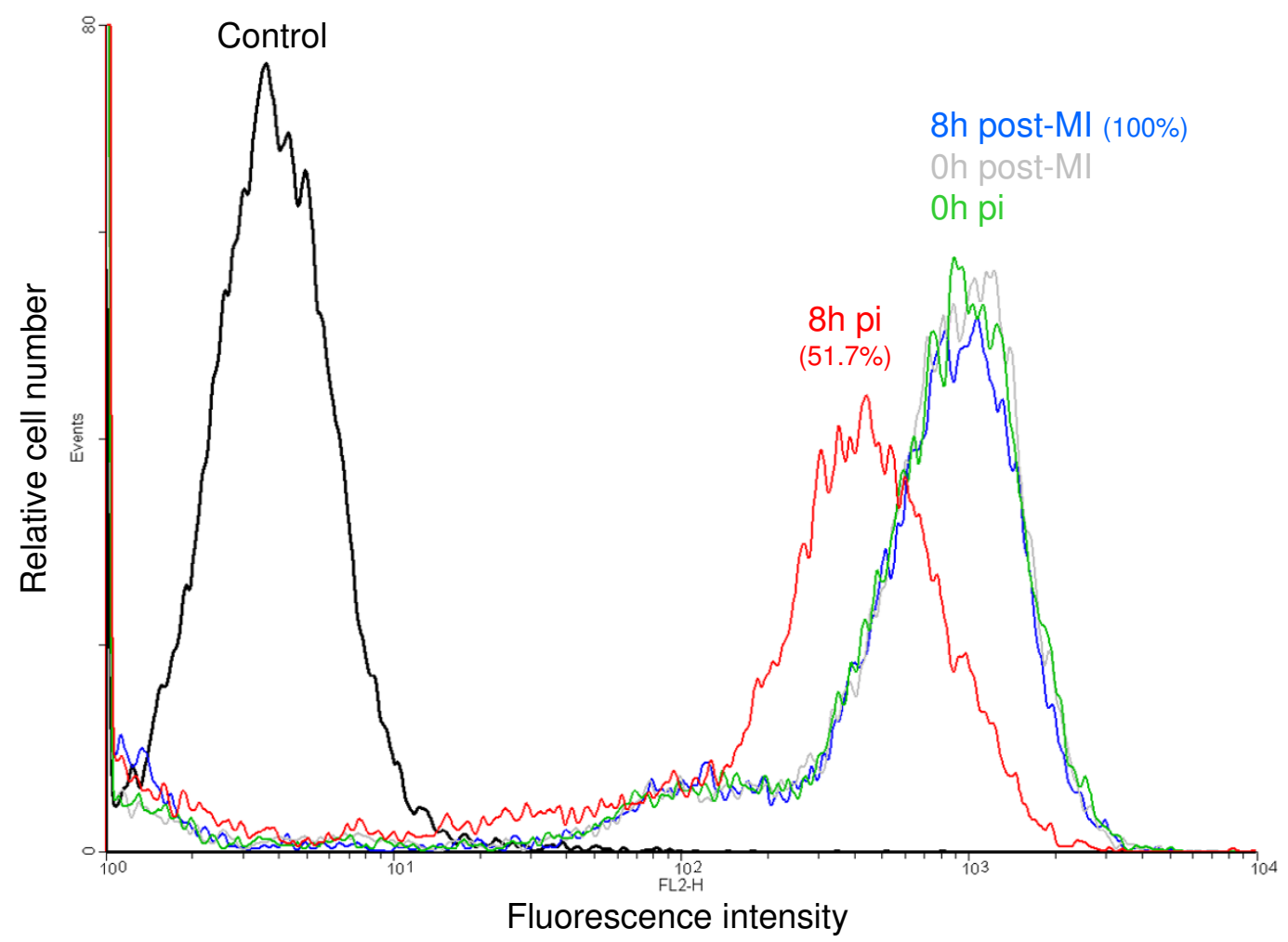

\section{Figure 5}

SLA I cell surface decrease on PrV infected PKI 5 cells. Histogram overlays of MHC class I expression detected by the mAb PT85A are shown. The number in red represents the percent mean fluorescence intensity [(mean channel fluorescence of the infected sample at $8 \mathrm{~h} \mathrm{pi/mean} \mathrm{channel} \mathrm{fluorescence} \mathrm{of} \mathrm{the} \mathrm{mock-infected} \mathrm{cells} \mathrm{at} 8 \mathrm{~h} \mathrm{pi}$ ) $\times 100]$. The results represent one of three representative experiments. 
from $4 \mathrm{~h}$ pi (non structural, capsid, tegument and envelope protein transcripts). The molecular hallmark of herpesvirus infection is a temporally ordered gene transcription. As for other herpesviruses, the PrV genes are subdivided in three main classes of successively expressed transcripts: immediate early, early and late transcripts [1]. After binding of the viral particle and fusion of the virion envelope with the cell membrane, the release of capsid and tegument proteins into the cell and the takeover of host cell protein synthesis machinery, the IE 180 protein encoded by the immediate early gene is expressed in the cytoplasm and translocated to the nucleus. This protein can further transactivate the RNA polymerase II mediated transcription of early genes including transactivators of transcription (EP0, US1, UL54) and proteins essential for viral replication (UL5, UL8, UL9, UL29, UL30, UL42, UL52, UL28, UL39, UL40, UL23, UL50, UL12, UL2) [1]. The expression of IE180 has been reported to begin between $40 \mathrm{~min}$ and $1 \mathrm{~h}$ pi and last until $3 \mathrm{~h}$ pi [1]. In our experiment, the IE180 probe (IEP2) was differentially expressed only at $4 \mathrm{~h} \mathrm{pi}$, when the transcript level probably reaches its peak value. This suggests that a low level of IE180 transcripts is sufficient to induce the transcription of early genes. In this experiment, the differential expression of US1 and UL29 was detected as early as $1 \mathrm{~h}$ pi but other early genes appeared differentially expressed later. Interestingly, the UL49.5 probe corresponding to the $\mathrm{gN}$ protein, responsible for TAP inhibition, was differentially expressed at $1 \mathrm{~h} \mathrm{pi}$, even if this gene is not described as an early gene. The synthesis of late proteins, such as capsid (UL6, UL18, UL19, UL25, UL35 and UL38), tegument (UL11, UL13, UL16, UL21, UL36, UL37, UL37, UL41, UL46, UL47, UL48, UL49, UL51, US3, US2) and envelope proteins (gE, gI, gD, gM, gH, gC, gB, gN, gK) are reported to occur during the PrV replication cycle [1]. In our study, the two late transcripts UL6 and UL22 encoding the gH protein were differentially expressed as early as $2 \mathrm{~h}$ pi. The four latest differentially expressed genes mostly encoded envelope or tegument proteins, except UL9.

We described for the first time a global analysis of $\operatorname{PrV}$ gene transcription using a microarray. The results of our analysis is consistent with what is known about $\operatorname{PrV}$ viral cycle and with the kinetic classification of individual transcripts [1]. Similar approaches have been developed for other alphaherpesviruses such as HSV-1 $[28,29]$ and Varicella-Zoster virus (VZV) $[28,29]$. It is difficult to compare our results with those obtained in the VZV study because this viral system does not allow cell infection under single cycle synchronized conditions (one limitation of this viral system), which is required to establish reliable kinetics of viral gene expression. However our results are consistent with the transcriptomic study reported for HSV-1 $[28,29]$. It is clear from figure 3 that PrV early homologues of HSV1 immediate early genes (EPO, UL54, US1) and early genes (UL23 encoding thymidine kinase, UL30 encoding a DNA polymerase subunit, UL39 encoding the large subunit of ribonucleotide reductase) are expressed at early times before most of the late genes encoding structural proteins. A clear distinction between immediate early, early and late genes for $\operatorname{PrV}$ will require transcriptomic analysis in the presence of the translation inhibitor cycloheximide (to identify immediate early genes) or the viral DNA replication inhibitor phosphonoacetic acid (to distinguish early and late genes) as was done for HSV-1 $[28,29]$.

\section{PrV and cellular shutoff}

A cellular shutoff during infection has been described for herpesviruses including PrV [1]. In our experiment, a shutoff of PK15 genes is observed during infection since many cellular genes are down-regulated between 4 and $12 \mathrm{~h}$ pi. In contrast, at the $4 \mathrm{~h}$ time point, $42.5 \%$ of the viral genes are up-regulated. Our transcriptomic analyses reveal that the shutoff occurs in porcine cells earlier than that previously reported in other transcriptome studies i.e. between 8 and $12 \mathrm{~h}$ pi in rat embryonic fibroblasts and from $6 \mathrm{~h}$ pi in human embryonic kidney cells [12,14]. It is assumed that the virion host shutoff protein (vhs/UL41 transcript) causes cellular shutoff. The vhs protein is an RNAse located in the viral tegument, which degrades host and viral RNA just after infection for HSV-1 [30]. Unlike HSV1 , it has been suggested that for cellular shutoff, PrV requires a fresh round of viral protein synthesis explaining the observed delayed shutoff [9]. In our experiment, UL41 transcripts appear to be differentially expressed only at 8 $\mathrm{h}$ pi suggesting that the vhs activity can be attributed to the newly synthesized proteins and not to the vhs proteins present in the virion tegument at the moment of infection and that the vhs protein should be active at low level. The activity of HSV-1 vhs is modulated by the UL48 product (VP16), which can bind to vhs to allow viral mRNA accumulation [31]. However, our study does not show any differential expression of the UL48 transcript.

\section{PrV infection and immune evasion strategies}

To evade host response PrV develops several strategies that probably disturb different biological pathways including the MHC class I presentation pathway. We observed a decrease of SLA-Ia and TAP2 transcript levels in PK15 cells infected with the PrV NIA3 strain as previously reported in infected PK15 and bovine kidney cells respectively (INDF PrV strain) [9]. A down-regulation of TAP1 and TAP2 genes encoding immunoproteasome catalytic subunits, PSMB8 and PSMB9, involved in the MHC class I antigenic presentation pathway was also detected in our experiment. Moreover, we checked that at $8 \mathrm{~h}$ pi the PK15 cells expressed 50\% less MHC class I proteins than mockinfected cells in our culture conditions. These results confirm previous reports describing the reduced capacity of 
infected cells to present viral peptides to CTL $[6,7]$. The viral gene UL49.5, encoding the gN protein, is one of the earliest differentially expressed genes in our study (from 1 $\mathrm{h}$ pi). This viral protein has been shown to inhibit TAP activity and induce degradation of TAP molecules by the proteasome $[5,8,32]$. Our results strongly suggest a very early production of gN protein and agree with the detection of TAP inhibition from $2 \mathrm{~h}$ pi [7]. This TAP inhibition has been shown to be independent of vhs activity [9] and we demonstrate here that UL41 encoding vhs is differentially expressed later than UL49.5, indicating two successive steps i.e. TAP inhibition followed by cellular shutoff. Since the level of several transcripts involved in the MHC class I presentation pathway (MHC class Ia, TAP1, TAP2, PSMB8 and PSMB9) decreased, it is possible that PrV has developed complementary strategies to evade this pathway i.e. turning off the peptide pump with inhibition of TAP activity and transcription alteration of key players [5]. Other viruses, such as the human cytomegalovirus, downregulate the transcription of key players of the MHC class I antigen presentation pathway [5]. Unexpectedly, some MHC class II genes were also regulated during PrV infection in PK15 cells. In particular, a down-regulation of class II-like chaperones SLA-DOB and SLA-DMB was observed. MHC class II molecules that are constitutively expressed on professional antigen presenting cells (APCs), present peptides derived from exogenous antigens to CD4+ T-helper cells playing an important role in the induction and maintenance of CTL immunity. Epithelial cells can also constitutively express MHC II molecules but at a lower level than professional APCs [33]. In our experiment, we detected a small subpopulation of uninfected PK15 cells constitutively expressing MHC class II molecules. However, we did not detect modifications of the MHC class II expression at the cell surface. Since a downregulation of constitutive and IFN $\gamma$ induced HLA class II expression has been observed in cells infected by other herpesviruses [33], our preliminary data suggest that it would be highly relevant to explore how PrV may interfere with the MHC class II presentation pathway in professional APCs.

In addition to genes belonging to MHC antigen presentation pathways, several other genes, playing a role in antiviral response are regulated during PrV infection such as genes belonging to the IFN signaling pathway. Indeed, it has been reported that in primary rat fibroblasts, $\operatorname{PrV}$ infection could suppress the establishment of the IFN $\beta$ induced viral state [13]. IRF3, which is a transcriptional factor involved in IFN $\beta$ production by epithelial cells, is down-regulated together with a set of other IRF. Constitutively expressed in the cytosol, IRF3 is phosphorylated during herpesvirus infection and translocated into the nucleus to target the IFN $\beta$ promoter. Many viruses interfere with IRF activities [34]. A decrease of IRF1 mRNA and protein levels has also been detected in cells infected with hepatitis $\mathrm{C}$ virus, resulting in the transcriptional repression of several IFN-stimulated genes [35]. In addition, TNF-alpha, which is a multifunctional cytokine with potent antiviral activities and which mediates protection against HSV-1 in the mouse [36] was analyzed by qRTPCR. A strong up-regulation of TNF was detected from the beginning of PrV infection and until $12 \mathrm{~h}$ pi. These results suggest that the TNF transcription increase that is usually expected during an infection is not suppressed by $\operatorname{PrV}$ infection and that the cellular shutoff does not target TNF.

\section{Other cellular pathways modulated during $\operatorname{PrV}$ infection}

Our transcriptome analysis confirms that many other biological processes and functions are modulated during $\operatorname{PrV}$ infection in porcine PK15 cells as previously observed in rat embryonic fibroblast and human embryonic kidney cells $[12,14]$. We have focused our study on a limited number of pathways and genes. Interestingly, we observe both by transcriptome analysis and qRT-PCR that PPIA gene expression is clearly down-regulated during $\mathrm{PrV}$ infection. PPIA encodes cyclophilin A, a peptidyl-prolyl isomerase, which catalyzes the isomerization of peptide bonds from the trans to cis form at proline residues and facilitates protein folding [37] and which acts as a cytosolic molecular chaperone. Cyclophilins have been discovered because of their high affinity for cyclosporine, an immuno-suppressive drug, which prevents allograft rejection. This immunosuppressive effect is due to the calcineurin inhibition by a cyclosporin-cyclophilin complex. Calcineurin is required for transcriptional activation of many cytokines in stimulated T cells. Cyclophilin A can also interact with HIV-1 Gag polyprotein and is involved in HIV-1 replication kinetics and modifies the infectivity of HIV-1 virions in Jurkat T cells [38]. Indeed, virions produced by PPIA $\%$ cells are less infectious than virions produced by $\mathrm{PPIA}^{+/+}$cells. Since we observed a downregulation of PPIA before the global cellular shutoff, cyclophilin A may be a target for PrV and play a role in infection via an unknown mechanism.

Several cellular genes involved in apoptosis were regulated during $\mathrm{PrV}$ infection such as $\mathrm{BCl}-2$ molecules and caspases. Viral infection of mammalian cells tends to generate proapoptotic signals to limit viral replication but viruses and, in particular, herpesviruses produce molecules acting as modulators of apoptosis [1]. Thus, US3 products from PrV play an anti-apoptotic role [39]. The PIKNIA3 probe specific to US3 long and short isoform transcripts was up-regulated from $8 \mathrm{~h}$ pi in our experiment, suggesting a possible late antiapoptotic role of the US3 products. In addition, PrV genes homologous to other HSV-1 antiapoptotic genes may also possess an antiapoptotic role such as UL54 or US1 [1]. UL54 was not 
differentially expressed in our experiment in contrast to US1, which was up-regulated very early as soon as $1 \mathrm{~h}$ pi.

Genes belonging to nucleic acid metabolism were differentially expressed from very early time points. A repression of many genes encoding histones and nucleosome components occurred in PK15 cells during infection. These results are concordant with a former study, which has shown a gradual inhibition of histone synthesis in RK13 rabbit cells during PrV infection [40]. We also observed a modulation of many histone deacetylases (HDAC). Acetylation of newly synthesized histones is required for their assembly into nucleosomes by histone chaperones and regulates the formation of heterochromatin that is critical for cellular gene transcription. US3, which was up-regulated from $8 \mathrm{~h}$ pi in our experiment, can suppress histone acetylation during HSV1 infection [41]. Indeed, PrV US3 could also inhibit histone acetylation during infection.

PrV infection regulates the expression of several genes involved in actin cytoskeleton signaling. A probe specific to ACTG1 was strongly up-regulated as soon as $1 \mathrm{~h}$ pi and reached a peak at $4 \mathrm{~h}$ pi. Cytoskeleton actin is involved in $\mathrm{PrV}$ assembly and in virus movement within the host cell. In particular, viral capsids can travel along nuclear actin filaments using myosin-directed transport in neurons but also in PK15 cells [42]. Moreover, actins present in the nucleus participate in transcription [43]. Among PrV proteins, the US3 protein kinase contributes to cellular cytoskeleton modifications via the formation of actinand microtubule-containing cell projections, a phenomenon associated with an increase of PrV intercellular spread [44].

\section{Conclusion}

The originality of our approach lies in the simultaneous investigation of transcript levels of both host and pathogen genomes using a partial generic microarray and a dedicated microarray (SLA/PrV) combining all the PrV genes and probes from the SLA complex. It is now necessary to extend our analysis of the interactions between $\operatorname{PrV}$ and porcine cells to other target cells, such as immature dendritic cells (iDC) that are the first immune cells interacting with the virus. This kind of approach should also be efficient (i) to study viral and cellular gene expression using mutant viruses in order to better understand the role of each viral gene and (ii) to help identify species or strain specific transcriptomic signatures in host cells.

\section{Methods \\ Cells, viruses and infection}

The PK15 cells used in this study, for both viral stock production and virus-cell interaction experiments, were propagated in the H-MSM aproteic synthetic medium (R.
L'Haridon, unpublished results) without serum. This medium consists in Eagle's Minimum Essential Medium (EMEM) supplemented with appropriate amounts of amino-acids, sugars, vitamins, salts and organic acids and without any additional hormone, natural or recombinant protein or growth factors. The PK15 cells underwent at least 40 passages in these conditions prior to this study.

The virulent wild type NIA3 strain of Pseudorabies virus as well as its GFP expressing derivative were grown by infecting confluent PK15 cell monolayers in $175 \mathrm{~cm}^{2}$ flasks (Corning, France) at a MOI of 0.1 . After a $48 \mathrm{~h}$ growth period, the cell culture medium, containing progeny virions, was collected, chilled on ice and clarified by centrifugation at $4^{\circ} \mathrm{C}$. Virions were purified by ion exchange chromatography on Sartobind S cation exchanger membranes (Sartorius, Palaiseau, France) as described previously [45] except that SingleSep minicapsules were used instead of the MA100 device. After concentration by ultracentrifugation (Beckman SW41 rotor, 25,000 rev per min, $1 \mathrm{~h}, 4^{\circ} \mathrm{C}$ ) purified virions were resuspended in TBSal buffer ( $200 \mathrm{mM} \mathrm{NaCl}, 2.6 \mathrm{mM} \mathrm{KCl}, 10 \mathrm{mM}$ Tris- $\mathrm{HCl}, \mathrm{pH}$ $7.5,20 \mathrm{mM} \mathrm{MgCl} 2,1.8 \mathrm{mM} \mathrm{CaCl} 2)$ and stored in aliquots at $-80^{\circ} \mathrm{C}$.

Infectious virus titers in purified stocks or cell culture supernatants were determined by plaque assay on PK15 cells grown in standard conditions (EMEM containing 10 $\%$ fetal calf serum) as described previously [46].

For virus-cell interaction experiments, aliquots of PK15 cells were seeded in $50 \mathrm{~mm}$ Petri dishes. We used the same batch of cells to prepare all the aliquots of the same timecourse replicate experiment. When cells reached confluence, growth medium was removed and replaced by the inoculum (purified virions at a MOI of 20 diluted in a small volume of fresh medium) for infection by the mockinoculum (virus resuspension buffer diluted the same way) for mock-infection. After a $45 \mathrm{~min}$ adsorption period at room temperature, inoculums and mock-inoculums were removed and replaced, after a single rinse, by $\mathrm{H}-\mathrm{MSM}$. At this time (considered as T0) monolayer cultures were further incubated at $37^{\circ} \mathrm{C}$ for the time required before RNA extraction. For flow cytometry experiments (see below), we used the same procedure except that the cells were mock-infected or infected with a recombinant PrV strain (derived from the NIA3 strain) that constitutively expresses the GFP under the control of the immediate-early promoter of HCMV (M. Cochet and F. Lefèvre, unpublished data). Cells were analyzed $8 \mathrm{~h}$ post-infection and we performed three replicate experiments.

\section{RNA isolation}

Cells were harvested for RNA extraction just after infection or mock-infection (time 0), and 1, 2, 4, 8 and 12 hours 
after infection or mock-infection. RNA was extracted with the Trizol-chloroform method (Invitrogen, France), dissolved in $40 \mu \mathrm{l}$ DEPC treated water and quantified (Nanodrop, nyxor Biotech). For quantitative real-time RT-PCR, RNA was treated with DNase I and cleaned to remove any DNA contamination (DNase set and cleanup, Qiagen, France). RNA quality was checked on the Bioanalyzer Agilent (Agilent Technologies, France) and RNA with a RIN score between 8 and 10 were labeled and used in microarray or qRT-PCR experiments. The RNA were diluted at $1 \mu \mathrm{g} / \mu \mathrm{l}$ final concentration and stored at $-80^{\circ} \mathrm{C}$.

\section{Design and production of the SLA/PrV microarray}

The SLA/PrV microarray, composed of cDNA and subcloned exons, is a dedicated array containing porcine and PrV probes, which was produced by the CRB-GADIE (Centre de Ressources Biologiques pour la Génomique des Animaux Domestiques et d'Intérêt Economique, LREG, INRA, Jouy-en Josas, France). The list of genes present in the human SLA orthologous region (6p21-p23) established using the human sequence draft (May 2004) on UCSC web site [47] and porcine cDNA clones were selected when they were available in the AGENAE library [19] or in two American libraries MARC1PIG and MARC2PIG constructed by the United States Department of Agriculture (USDA). When no porcine cDNA clone was found, exons were identified by comparison between ESTs and genomic DNA using the ICCARE comparison mapping tool $[48,49]$. Primers were designed with Primer 3 [50].

To design the PrV amplicons, we first established a complete composite sequence of the $\operatorname{PrV}$ genome by merging genomic sequences available in Genbank from seven strains of PrV. Positions of the 5' and 3' ends of viral transcripts (true or putative) as well as ORFs were established according to published data or Genbank annotations (F. Lefevre, unpublished). The location of the 80 amplicons, at least one per transcript, was chosen according to this map, generally close to the 3 ' end of the transcripts (Figure 1 ). In the case of nested transcription units, we designed as many amplicons as the number of nested transcripts so that each amplicon was located between the 5' ends of two consecutive transcripts. We used Primer 3 to design primers for amplification ( 30 cycles: $30 \mathrm{sec}$ at $94^{\circ} \mathrm{C}, 30$ sec at $60^{\circ} \mathrm{C}$ and $30 \mathrm{sec}$ at $72^{\circ} \mathrm{C}$, in the presence of $10 \%$ DMSO). PrV probes targeting 70 viral genes [see Additional file 3] and pig exons were subcloned in PGEM-T easy plasmid (Promega, France) and individual clones checked for correct amplification by sequencing. For the SLA and immune clones spotted on the SLA/PrV slides, sequence homology was checked by multi-alignment (BLAST) against human and pig EST databases [21,51]. The SLA/PrV microarray probes were reannotated taking into account the most significant BLAST results and its final geneID file was used in the analysis.

Plasmid clones bearing cDNAs, sub-cloned exons or PrV amplicons were used as templates for preparative PCR (Taq PCR Master Mix Kit, Qiagen, France) with universal primers located in the vector ( 35 cycles, same conditions as above for $\operatorname{PrV}$ amplicons and $30 \mathrm{sec}$ at $94^{\circ} \mathrm{C}, 30 \mathrm{sec}$ at $60^{\circ} \mathrm{C}$ and $2 \mathrm{~min}$ at $70^{\circ} \mathrm{C}$ for other probes). After purification (Multiscreen-PCR plates, Millipore, France), PCR products were checked on $1 \%$ agarose gel, quantified using Fluoroskan Ascent (Thermo Fischer Scientific, France), evaporated and pellets were resuspended in $13 \mu \mathrm{l}$ SSC3X. Forty-six control spots were added to the slide (Lucidea Universal Scorecard, Amersham Biosciences, France). Two identical arrays were spotted on slides $(25 \times$ $75 \mathrm{~mm}$, UltraGAPS Coated Slides, Corning) with a 16 needle spotter (Microarraywriter Pro, Virtek, France). After spotting, slides were first treated with steam to homogenize the hydration of spots. Then, spotted DNA was denatured $\left(5 \mathrm{sec}\right.$ at $\left.100^{\circ} \mathrm{C}\right)$ and UV fixed $(300 \mathrm{~mJ})$. Slides were stored in dry atmosphere before use.

The SLA/PrV DNA/cDNA microarray platform has been submitted to the Gene Expression Omnibus (GEO) repository [52]. The accession number is GPL5622.

\section{The generic porcine array}

The second microarray is a commercial generic microarray spotted on slides (Qiagen-NRSP8) and contains 13297 oligonucleotides (70-mers) specific of 8541 porcine genes [17]. The microarrays used in this study were provided by Dr Max Rothschild (Department of Animal Science, Iowa State University). We used the annotation of QiagenNRSP8 slides given by Zhao and collaborators [17].

\section{RNA labeling, hybridization scheme, microarray scanning and signal quantification}

Five $\mu \mathrm{g}$ of each RNA were reverse-transcribed and labeled with Cy3 and Cy5 (reagents: Pronto kit, Corning and Amersham, Biosciences). Labeled targets were quantified (Nanodrop, Nyxor Biotech, France), evaporated and the pellets were resuspended in hybridization buffer (Pronto Kit, Corning, France) at a final concentration of 2 pmoles/ $\mu$ l. Control RNA (Spikes, Lucidea Universal Scorecard, Amersham Biosciences, France) specific to the control spots on the SLA slides were labeled together with total RNA.

All time points (T0, T1, T2, T4, T8 and T12 h pi) for SLA/ PrV hybridizations and only four time points for QiagenNRSP8 hybridizations (T1, T2, T4 and T8 h pi) were used. Twelve and eight different conditions were considered for the SLA/PrV and Qiagen-NRSP8 hybridizations, respectively. The hybridization scheme which can be defined as 
dye-switch was chosen to minimize the number of slides used and to test the impact of several factors on the results (conditions, labeling protocol, networks, day of experimentation and samples). A balanced loop design with two independent loops, each loop containing two replicates of PrV infection and mock-infection, was used (Figure 6). In total, 24 SLA/PrV slides and 32 Qiagen-NRSP8 slides were used in this experiment. All slides were processed in the same conditions. The slides were pre-soaked, prehybridized and hybridized with the same quantity of Cy3 and Cy5 labeled cDNA: 20 and 40 pmoles of each labeled cDNA for the SLA/PrV slides and for the QiagenNRSP8 slides, respectively (Pronto Kit, Corning, France). After hybridization for 16 hours at $42^{\circ} \mathrm{C}$, the slides were washed according to a commercial protocol (Pronto kit, Corning, France) and dried by centrifugation (1500 rpm, $3 \mathrm{~min})$.

SLA/PrV and Qiagen-NRSP8 slides were scanned on the Scanarray scanner (Perkin Elmer, France) and on the Microarrayreader scanner (Virtek, France), respectively.
Signals were quantified with the Imagene version 5.1 software (Biodiscovery, USA). All the results were stored in the BioArray Software Environment (BASE) of SIGENAE (Système d'Information du projet d'Analyse des Genomes des Animaux d'Elevage) [20].

The SLA/PrV and the Qiagen-NRSP8 microarray data have been submitted to the GEO and received accession numbers GSE8676 and GSE9259, respectively.

\section{Statistical data analysis}

The normalization and statistical analysis steps were performed with scripts written with R software. Functions contained in stats, anapuce and varmixt packages were used. Raw data were $\log 2$ transformed, normalized by lowess ( $f=0.3$ ) and the median of each block spotted on the slide was subtracted. Normalized data were analyzed with a linear model. For one gene and one target, the following linear model was used:

$$
\mathrm{Y}_{\mathrm{cfnds}}=\mu_{\mathrm{c}}+\alpha_{\mathrm{f}}+\beta_{\mathrm{n}}+\delta_{\mathrm{d}}+\varepsilon_{\mathrm{s}}+\mathrm{E}_{\mathrm{cfnds}}
$$
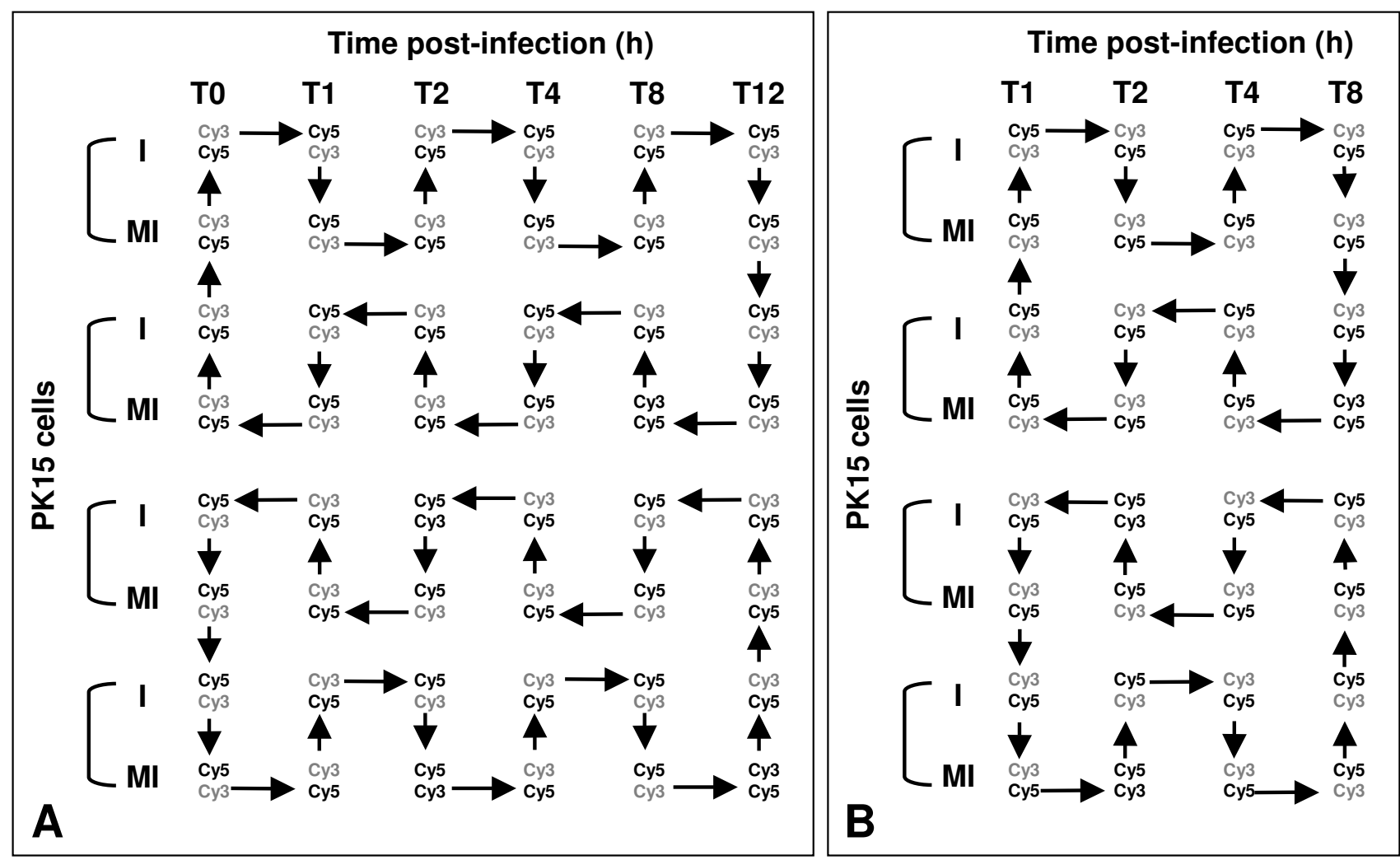

Figure 6

Hybridization scheme of the SLA/PrV and the Qiagen-NRSP8 microarrays. A Hybridization scheme of the SLA/PrV microarrays. Forty-eight hybridizations corresponding to 24 PrV/SLA slides were hybridized (two arrays per slide, see Methods). B Hybridization scheme of the Qiagen-NRSP8 microarrays. Thirty-two Qiagen-NRSP8 slides were hybridized. Each labeled target is represented by its dye Cy3 or Cy5. Each arrow linking Cy3 to Cy5 represents one hybridization on one array. 
with $\mathrm{Y}_{\mathrm{cfnds}}=$ normalized intensity, $\mu_{\mathrm{c}}=$ condition effect $(1$ $\leq \mathrm{c} \leq \mathrm{o}), \alpha_{\mathrm{f}}=$ fluorochrome effect $(1 \leq \mathrm{f} \leq 2), \beta_{\mathrm{n}}=$ network effect $(1 \leq \mathrm{n} \leq \mathrm{q}), \delta_{\mathrm{d}}=$ effect of experiment day $(1 \leq \mathrm{d} \leq 2)$, $\varepsilon_{\mathrm{s}}=$ sample effect $(1 \leq \mathrm{s} \leq \mathrm{r}), \mathrm{E}_{\mathrm{cfnds}}=$ random error, $\mathrm{o}=$ number of conditions, $\mathrm{q}=$ number of arrays, $\mathrm{r}=$ number of samples. Since the effect of samples was not significant (Student t test, p > 0.05), we did not keep it in the final linear model. Selected contrasts (defined by a linear combination of 2 or more factor level means with coefficients that sum to zero) were tested with the Student t test: infected condition against mock-infected condition at each time point. The differences observed for one time point were tested taking into account all the data for all the time points leading to a powerful statistical test. The false Discovery Rate (FDR) was calculated after the Student $\mathrm{t}$ test ( $\mathrm{R}$ software, varmixt package). We selected differentially expressed genes with an FDR $=0.05$.

Hierarchical clustering analysis (HCL, Eisen) was performed to analyze viral genes and cellular genes that were differentially expressed during infection (euclidian distance, average linkage) using TMeV software [53]. Averages of normalized intensities for all the mock-infected conditions and for each infected condition were calculated and these values were centered (median) by genes. The "k-means" method was used to identify groups of genes with similar expression kinetics (TMeV software, [53]). The optimal number of groups was determined by the "Figure of Merit" method (FOM).

\section{Functional analysis/Network and pathway analysis}

The "Gene Ontology" annotations of differentially expressed cellular genes were obtained with the Panther software based on human orthologous genes [54]. The biological process sub-ontology was used to classify genes in different functional groups. The Ingenuity Pathways
Analysis (IPA) program permitted the determination of the significant networks and the top functions associated with the differentially expressed genes at each time point (IPA 5.0, Ingenuity Systems Inc., USA; [55]). The IPA program searches the Ingenuity Pathway Knowledge Base (IPKB) for interactions (known from the literature) between the uploaded genes and all other genes contained in IPKB and generates a series of networks. The genes selected by the IPA network analysis are called focus genes. The Fisher exact test was used to assign statistical significance, and each network's score is displayed as the $\log$ (P-value). Significant networks with a score greater than 3 were selected $(\mathrm{p}<0.001)$ and top functions associated with these networks are presented (Table 4).

\section{Quantitative real time RT-PCR (qRT-PCR)}

RNAs corresponding to mock-infected T0 and T1 and infected T0, T2, T4, T8, T12 samples from three replicates were used for real-time PCR analysis. Primers were chosen with the Primer express software or manually, one of each primer couple located on the exon-exon boundary (Table $7)$. Five differentially expressed porcine genes and two other porcine genes were chosen for real-time PCR testing. Each amplicon was sequenced and its sequence was aligned with the gene reference sequence. Two and a half $\mu \mathrm{g}$ of cleaned total RNA were reverse transcribed using Superscript II enzyme (Invitrogen, France) with Oligo(dT) primers (Invitrogen, France) and cDNAs were quantified with the 2100 Bioanalyzer (Agilent Technologies, France) and diluted to obtain a $30 \mathrm{ng} / \mu \mathrm{l}$ final concentration for all samples. Triplicate reactions were set up in a $20 \mu$ l volume using 10 ng cDNA, PCR primers (300 nM final concentration) and SYBR Green PCR Master Mix (Applied Biosystem, USA). An ABI PRISM 7900 HT sequence detection system was used for monitoring the level of SYBR green fluorescence. A dissociation curve was produced at the

Table 7: Sequence of primers for qRT-PCR.

\begin{tabular}{|c|c|c|c|}
\hline Target & Oligo & Sequence & Size(bp) \\
\hline \multirow[t]{2}{*}{ RPL32 } & forward & TGCTCTCAGACCCСTTGTGAAG & 22 \\
\hline & reverse & TTTCCGCCAGTTCCGCTTA & 19 \\
\hline \multirow[t]{2}{*}{ SLAla } & forward & CATCATTGTTGGCCTGGTTC & 20 \\
\hline & reverse & ССТTTTTCACCTGAGCGC & 18 \\
\hline \multirow[t]{2}{*}{ TAPI } & forward & CCAGTATCTCAGGGATGTTGCTG & 23 \\
\hline & reverse & CGCTGCTTATAGCCCCACC & 19 \\
\hline \multirow[t]{2}{*}{ TAP2 } & forward & TGTTGGGTGAGACACTAATCCCTTA & 25 \\
\hline & reverse & CAAAGGCATCAGGGTCAAAATC & 22 \\
\hline \multirow[t]{2}{*}{ PSMB9 } & forward & GCGCTTCACCACAAATGCTA & 20 \\
\hline & reverse & TCCACACCAGCAGCTGTAATG & 21 \\
\hline \multirow[t]{2}{*}{ PSMB8 } & forward & TACCTGCTTGGCACCATGTCT & 21 \\
\hline & reverse & AGTACAACCTGCACTCCTTGGC & 22 \\
\hline \multirow[t]{2}{*}{ PPIA } & forward & GTCTCCTTCGAGCTGTTTGCA & 21 \\
\hline & reverse & CCAAATССТTTСТССССAGTG & 21 \\
\hline \multirow[t]{2}{*}{ TNF } & forward & CCCAAGGACTCAGATCATCGTC & 22 \\
\hline & reverse & AGCTGTCCCTCGGCTTTGA & 19 \\
\hline
\end{tabular}


end of the cycling phase to ensure a single PCR product and no primer dimer. Amplification efficiencies were determined for all genes by serial dilution of cDNA using $\mathrm{E}=10^{[-1 / \text { slope] }}$. We checked that a slope between -3.2 and 3.5 was obtained for each primer couple to calculate the relative expression levels of the selected genes by using the $2-\Delta \Delta \mathrm{Ct}$ method. The gene encoding Ribosomal Protein L32 (RPL32) was chosen as the internal reference for each sample. The mock-infected sample at T0 of each replicate was used as a calibrator for all samples of one replicate. The mean and the standard deviations for each time of each replicate were calculated.

\section{Flow cytometry}

The anti-porcine MHC class I monoclonal antibody (mAb) PT85A and the anti-porcine MHC class II mAb MSA3 were purchased from VMRD (USA). The mAb HOPC-1 (IgG2a, Beckman Coulter, USA) was used as control Ab. PE-conjugated goat Abs to mouse IgG2a were purchased from Southern Biotech (USA).

PK15 cells from three kinetics replicates, either just after mock-infection or infection with the GFP-expressing PrV strain and $8 \mathrm{~h}$ after mock-infection or pi were trypsinized, resuspended in pig serum for 20 minutes at $4{ }^{\circ} \mathrm{C}$, washed in D-PBS and resuspended in FACS buffer. Cells were incubated with $50 \mu \mathrm{l}$ of diluted primary antibody $(1 / 200$ in FACS Buffer) for 30 minutes at $4^{\circ} \mathrm{C}$ and then, after washing, in $50 \mu \mathrm{l}$ of diluted PE-conjugated goat antimouse IgG2a (Jackson ImmunoResearch Laboratories, 1/ 600 in FACS Buffer) for 30 minutes at $4{ }^{\circ} \mathrm{C}$. After two washes in FACS Buffer, the cells were fixed in BD CellFix (BD Biosciences, USA) solution (1/10 in sterile D-PBS) and analyzed using a FACScalibur flow cytometer (BD Biosciences, USA).

\section{Competing interests}

The author(s) declare that they have no competing interests.

\section{Authors' contributions}

LF produced the SLA/PrV microarray, participated in the choice of the experimental design, performed RNA extractions, hybridizations, data analysis, qRT-PCR experiments, flow cytometry experiments and drafted the manuscript.

CRG participated in the coordination of the study, the SLA/PrV microarray design, the choice of the experimental design and corrected the manuscript.

MC produced the viral amplicons spotted on the SLA/PrV microarray.

GL participated in the qRT-PCR experiments.
$\mathrm{KH}$ assisted the design and the spotting of the SLA/PrV slide.

PC participated in the design of the SLA/PrV slide.

SR elaborated the experimental design and helped with the data statistical analysis.

FL participated in the coordination of the study, the design of the viral amplicons, produced the purified $\operatorname{PrV}$ virions, infected the PK15 cells and corrected the manuscript.

All authors have read and approved the final manuscript.

\section{Additional material}

\section{Additional file 1}

List of differentially expressed cellular genes spotted onto the SLA/PrV microarray.

Click here for file

[http://www.biomedcentral.com/content/supplementary/14712164-9-123-S1.doc]

\section{Additional file 2}

List of differentially expressed cellular genes spotted onto the QiagenNRSP8 microarray.

Click here for file

[http://www.biomedcentral.com/content/supplementary/14712164-9-123-S2.xls]

\section{Additional file 3}

Oligonucleotides used for production of PrV amplicons. Click here for file [http://www.biomedcentral.com/content/supplementary/14712164-9-123-S3.doc]

\section{Acknowledgements}

The authors wish to thank Dr René L'Haridon who provided the HMSM medium and PK 15 cells, Dr Isabelle Oswald (LPT, INRA, Toulouse, France) who provided some immunological probes spotted on the SLA/PrV microarray, Dr Xiao Xiang Hu (State Key Laboratory for Agrobiotechnology, China Agricultural University, Beijing, China) and Dr Christine Renard (LREG, INRA CEA, Jouy en Josas, France) who contributed to the selection of probes for the SLA/PrV microarray, Ms Céline Urien (LREG, INRA CEA, Jouy-en-Josas, France), M Jérome Lecardonnel and Ms Céline DucroixCrepy (CRBGADIE, INRA CEA, Jouy-en-Josas, France) for their technical assistance during the SLA/PrV microarray construction, Dr Sophie Pollet, and Ms Emmanuelle Zalachas (PICT Plateform, INRA, Jouy-en-Josas, France) for their technical assistance during the microarray experiment, $\mathrm{Dr}$ Claudia Bevilacqua (PICT Platform, INRA, Jouy-en-Josas, France) for her technical assistance during qRT-PCR experiments, Dr Sylvie Chevillard (DSV/IRCM/SREIT/LTE, CEA, Fontenay aux Roses, France) for the Scanarray access, M Philippe Bardou (SIGENAE, INRA, Toulouse, France), who helps us during GEO submission process, and finally Dr Wendy Brand Williams (SGQA, INRA, Jouy-en-Josas, France) and Dr Hélène Hayes (LGbC, INRA, Jouy-en-Josas, France) for the final read-through of the manuscript. 
This work was supported by the Genanimal funding (PRA 2004-B0I,

Agence Nationale de la Recherche, 2004-2007).

\section{References}

I. Pomeranz LE, Reynolds AE, Hengartner C): Molecular biology of pseudorabies virus: impact on neurovirology and veterinary medicine. Microbiol Mol Biol Rev 2005, 69:462-500.

2. Nauwynck H, Glorieux S, Favoreel H, Pensaert M: Cell biological and molecular characteristics of pseudorabies virus infections in cell cultures and in pigs with emphasis on the respiratory tract. Vet Res 2007, 38:229-24I.

3. Mettenleiter TC: Aujeszky's disease (pseudorabies) virus: the virus and molecular pathogenesis--state of the art, June 1999. Vet Res 2000, 31:99-II5.

4. Klupp BG, Hengartner CJ, Mettenleiter TC, Enquist LW: Complete, annotated sequence of the pseudorabies virus genome. J Virol 2004, 78:424-440.

5. Ambagala AP, Solheim JC, Srikumaran S: Viral interference with MHC class I antigen presentation pathway: the battle continues. Vet Immunol Immunopathol 2005, I 07: I - I 5.

6. Mellencamp MW, O'Brien PC, Stevenson JR: Pseudorabies virusinduced suppression of major histocompatibility complex class I antigen expression. J Virol I99I, 65:3365-3368.

7. Ambagala AP, Hinkley S, Srikumaran S: An early pseudorabies virus protein down-regulates porcine $\mathrm{MHC}$ class I expression by inhibition of transporter associated with antigen processing (TAP). J Immunol 2000, 164:93-99.

8. Koppers-Lalic D, Rijsewijk FA, Verschuren SB, JA GVB, Neisig A, Ressing ME, Neefjes J, Wiertz EJ: The UL4I-encoded virion host shutoff (vhs) protein and vhs-independent mechanisms are responsible for down-regulation of MHC class I molecules by bovine herpesvirus I. J Gen Virol 200 I, 82:207I-208I.

9. Ambagala AP, Gopinath RS, Srikumaran S: Inhibition of TAP by pseudorabies virus is independent of its vhs activity. Virus Res 2003, 96:37-48.

10. Jansen A, Yu J: Differential gene expression of pathogens inside infected hosts. Curr Opin Microbiol 2006, 9:| 38-| 142.

II. Jenner RG, Young RA: Insights into host responses against pathogens from transcriptional profiling. Nat Rev Microbiol 2005, 3:281-294.

12. Ray N, Enquist LW: Transcriptional response of a common permissive cell type to infection by two diverse alphaherpesviruses. J Virol 2004, 78:3489-350I.

13. Brukman A, Enquist LW: Suppression of the interferon-mediated innate immune response by pseudorabies virus. J Virol 2006, 80:6345-6356

14. Blanchard Y, Le MN, Le CM, Blanchard P, Leger J, Jestin A: Cellular gene expression survey of PseudoRabies Virus (PRV) infected Human Embryonic Kidney cells (HEK-293). Vet Res 2006, 37:705-723.

15. Tuggle CK, Wang Y, Couture O: Advances in swine transcriptomics. Int J Biol Sci 2007, 3: | 32-I52.

16. Renard C, Hart E, Sehra H, Beasley H, Coggill P, Howe K, Harrow J, Gilbert J, Sims S, Rogers J, Ando A, Shigenari A, Shiina T, Inoko H, Chardon $P$, Beck $S$ : The genomic sequence and analysis of the swine major histocompatibility complex. Genomics 2006, 88:96-I I0.

17. Zhao SH, Recknor J, Lunney JK, Nettleton D, Kuhar D, Orley S, Tug gle CK: Validation of a first-generation long-oligonucleotide microarray for transcriptional profiling in the pig. Genomics 2005, 86:618-625.

18. Ledger TN, Pinton P, Bourges D, Roumi P, Salmon H, Oswald IP: Development of a macroarray to specifically analyze immunological gene expression in swine. Clin Diagn Lab Immunol 2004, | |:69|-698.

19. Bonnet A, lannuccelli E, Hugot K, Benne F, Bonaldo MF, Soares MB Hatey F, Tosser-Klopp G: A pig multi-tissue normalised cDNA library: large-scale sequencing, cluster analysis and $9 \mathrm{~K}$ micro-array resource generation. BMC Genomics 2008, 9:17.

20. Système d'Information du projet d'Analyse des GENomes des Animaux d'Elevage (SIGENAE) 2007 [http://www.sige nae.org].

21. The Vertebrate Genome Annotation (VEGA) database 2007 [http://vega.sanger.ac.uk/index.html].
22. Bryant PA, Venter D, Robins-Browne R, Curtis N: Chips with everything: DNA microarrays in infectious diseases. Lancet Infect Dis 2004, 4:100-III.

23. Hossain $\mathrm{H}$, Tchatalbachev $\mathrm{S}$, Chakraborty $\mathrm{T}$ : Host gene expression profiling in pathogen-host interactions. Curr Opin Immunol 2006, I 8:422-429.

24. Lovegrove FE, Pena-Castillo L, Mohammad N, Liles WC, Hughes TR, Kain KC: Simultaneous host and parasite expression profiling identifies tissue-specific transcriptional programs associated with susceptibility or resistance to experimental cerebral malaria. BMC Genomics 2006, 7:295.

25. Zhang $Y$, Ohyashiki JH, Takaku T, Shimizu N, Ohyashiki K: Transcriptional profiling of Epstein-Barr virus (EBV) genes and host cellular genes in nasal NK/T-cell lymphoma and chronic active EBV infection. Br J Cancer 2006, 94:599-608.

26. Zhu B, Ping G, Shinohara Y, Zhang Y, Baba Y: Comparison of gene expression measurements from cDNA and 60-mer oligonucleotide microarrays. Genomics 2005, 85:657-665.

27. Wang HY, Malek RL, Kwitek AE, Greene AS, Luu TV, Behbahani B, Frank B, Quackenbush J, Lee NH: Assessing unmodified 70-mer oligonucleotide probe performance on glass-slide microarrays. Genome Biol 2003, 4:R5

28. Stingley SW, Ramirez J, Aguilar SA, Simmen K, Sandri-Goldin RM, Ghazal P, Wagner EK: Global analysis of herpes simplex virus type I transcription using an oligonucleotide-based DNA microarray. J Virol 2000, 74:99|6-9927.

29. Kennedy PG, Grinfeld E, Craigon M, Vierlinger K, Roy D, Forster T, Ghazal P: Transcriptomal analysis of varicella-zoster virus infection using long oligonucleotide-based microarrays. J Gen Virol 2005, 86:2673-2684.

30. Lin HW, Chang YY, Wong ML, Lin JW, Chang TJ: Functional analysis of virion host shutoff protein of pseudorabies virus. Virology 2004, 324:4I2-418.

31. Lam Q, Smibert CA, Koop KE, Lavery C, Capone JP, Weinheimer SP Smiley JR: Herpes simplex virus VPI6 rescues viral mRNA from destruction by the virion host shutoff function. $E M B O$ 1996, I5:2575-2581.

32. Abele R, Tampe R: Modulation of the antigen transport machinery TAP by friends and enemies. FEBS Lett 2006, 580: I I56- I I63

33. Wiertz EJ, Devlin R, Collins HL, Ressing ME: Herpesvirus Interference with Major Histocompatibility Complex Class IIRestricted T-Cell Activation. J Virol 2007, 8 I:4389-4396.

34. Honda K, Takaoka A, Taniguchi T: Type I interferon [corrected] gene induction by the interferon regulatory factor family of transcription factors. Immunity 2006, 25:349-360.

35. Ciccaglione AR, Stellacci E, Marcantonio C, Muto V, Equestre M, Marsili G, Rapicetta $M$, Battistini $A$ : Repression of interferon regulatory factor I by hepatitis $C$ virus core protein results in inhibition of antiviral and immunomodulatory genes. J Virol 2007, $81: 202-214$.

36. Lundberg P, Welander PV, Edwards CK, van RN, Cantin E: Tumor necrosis factor (TNF) protects resistant C57BL/6 mice against herpes simplex virus-induced encephalitis independently of signaling via TNF receptor I or 2. J Virol 2007, 81: | 451 - 1460 .

37. Andreeva L, Heads R, Green CJ: Cyclophilins and their possible role in the stress response. Int J Exp Pathol 1999, 80:305-3 I5.

38. Braaten D, Luban J: Cyclophilin A regulates HIV-I infectivity, as demonstrated by gene targeting in human $\mathbf{T}$ cells. EMBO J 2001, 20:1300-1309.

39. Geenen K, Favoreel HW, Olsen L, Enquist LW, Nauwynck HJ: The pseudorabies virus US3 protein kinase possesses anti-apoptotic activity that protects cells from apoptosis during infection and after treatment with sorbitol or staurosporine. Virology 2005, 33 I : |44-150.

40. Stevens JG, Kado-Boll G], Haven CB: Changes in nuclear basic proteins during pseudorabies virus infection. J Virol 1969, 3:490-497.

41. Poon AP, Gu H, Roizman B: ICPO and the US3 protein kinase of herpes simplex virus $I$ independently block histone deacetylation to enable gene expression. Proc Natl Acad Sci U S A 2006, 103:9993-9998.

42. Feierbach B, Piccinotti S, Bisher M, Denk W, Enquist LW: Alphaherpesvirus infection induces the formation of nuclear actin filaments. PLoS Pathog 2006, 2:e85. 
43. Pederson T, Aebi U: Nuclear actin extends, with no contraction in sight. Mol Biol Cell 2005, 16:5055-5060.

44. Favoreel HW, Van MG, Adriaensen D, Nauwynck HJ: Cytoskeletal rearrangements and cell extensions induced by the US3 kinase of an alphaherpesvirus are associated with enhanced spread. Proc Natl Acad Sci U S A 2005, 102:8990-8995.

45. Karger A, Schmidt J, Mettenleiter TC: Infectivity of a pseudorabies virus mutant lacking attachment glycoproteins $C$ and $D$. J Virol 1998, 72:734I-7348.

46. Riteau B, de VC, Lefevre F: Trypsin increases pseudorabies virus production through activation of the ERK signalling pathway. J Gen Virol 2006, 87: I 109- III 2.

47. University of California Santa Cruz (UCSC) Genome Bioinformatics 2007 [http://genome.ucsc.edu/].

48. Interface de Cartographie Comparée pour l'Agronomie et pour la Recherche sur I'Evolution (Iccare) web server 2007 [http://bioinfo.genopole-toulouse.prd.fr/iccare/].

49. Muller C, Denis M, Gentzbittel L, Faraut T: The Iccare web server: an attempt to merge sequence and mapping information for plant and animal species. Nucleic Acids Res 2004, 32:W429-W434.

50. Primer3 2007 [http://frodo.wi.mit.edu/cgi-bin/primer3/ primer3 www.cgi].

5I. The National Center for Biotechnology Information (NCBI) 2007 [http://www.ncbi.nlm.nih.gov/].

52. The Gene Expression Omnibus (GEO) 2007 [http:// www.ncbi.nlm.nih.gov/geo/]

53. TIGR MultiExperiment Viewer (TMeV) 2007 [http:// www.tm4.org/mev.html].

54. Panther Classification System 2007 [http://www.pantherdb.org/ ].

55. Ingenuity Pathways Analysis (IPA) 2007 [http://www.ingenu ity.com]

Publish with Biomed Central and every scientist can read your work free of charge

"BioMed Central will be the most significant development for disseminating the results of biomedical research in our lifetime. "

Sir Paul Nurse, Cancer Research UK

Your research papers will be:

- available free of charge to the entire biomedical community

- peer reviewed and published immediately upon acceptance

- cited in PubMed and archived on PubMed Central

- yours - you keep the copyright

Submit your manuscript here:

http://www.biomedcentral.com/info/publishing_adv.asp
BioMedcentral 